Hospital Roberto det Rio.

Clinica Oficial de Pediatria.

Prof. A. Sctoggio.

\title{
ENDOCARDITIS BACTERIANA SUBAGUDA
}

\section{(A proposito de 10 observaciones)}

\author{
Por el Dr. GASTON DUFFAU O.
}

Servicio de Cardiologia del Ho:pital "'Raberto del Rio'.

He creiclo de interés hacer algunas consideraciones sobre la endocarditis bacteriana subaguda en la infancia, a propósito de 10 observaciones reunidas en el Servicio de Cardiología del Hospital de Niños "Roberto del Río" desde 1934 a 1941 .

Es este un cuadro patológico de enorme importancia para los pediatras, ya que su profilaxis, único medio que tenemos para defendernos de él, se confunde con la profilaxis ce la enfermedad reumática, hecho que recae casi en forma exclusiva sobre nuestros hombros.

La división de la endocarditis bacteriana en forma aguda $y$ forma subaguda, tiene su justificación desde el punto de vista clínico y especialmente anatomopatológico. La primera forma es de corta duración, en general de curso rápico ry te. presenta un accidente, una complicación en el curso de una septicemia. Las lesiones anatómicas endocárdicas se caracte rizan por la escasez de procesos de reparación, predominando el factor destructivo, necrosante, de ahí su nombre de "encocardítis micótica alguda". En la forma subaguda, sucede generalmente lo invetso, en un miocardio anteriormente dañado, se anida una infección, secuela de una bacteriemia tran. s:toria, constituyéndose de esta manera en un foco produ:tor de bacterias. Es decir que en este caso, la endocarditis bacteriana constituye toda la enfermedad. Como los gérmenzs son de escasa virulencia, de poco poder necrosante, las manirestaciones destructivas disminuyen, para dar paso al proceso de reparación, el cual en raras ocasiones alcanza a la cicatrización total, dando así origen a la curación espontánea de esta enfermedad, ce pronóstico, si no siempre, en la mayoría cie los casos, fatal. 
Diremos dos palabras sobte la forma aguda de la endocarditis bacteriana, para individualizar mejor la forma subaguda.

\section{Endacarditis bacteriana aguda.}

La endocarditis bacteriana aguda es rara en la infancia, especialmente entre los 4 y il 4 años de edad, época de la vida en que la forma subaguda elige sus víctimas. Por debajo de lcs 4 años no constituye una excepción y sí es de extrema xareza, 1a presencia a esta edad de la forma subaguda.

Puede ser ocasionada por diversos agentes microbianos. siendo los más frecuentes, el estreptococo hemolítico, el estafilococo aureo, el neumococo, el gonococo. Como una localización más de una enfermedad aguda septicémica, estos bacterios se implantan generalmente en un corazón sano. Pero esto no disminuye la importancia que tiene la lesión reumática y la cardiopatía congénita como causas predisponentes.

La anatomia patológica, como he dicho, se caracteriza por el predominio Cel proceso necrosante sobre el de repatación. Las vegetaciones son friables, los bacterios penetrar. profundamente en el tejido valvular o en el muscular, en donde originan una miocarditis séptica. La rápida propagación del proceso destructivo, acarrea la ulceración de las vál. vulas o del septum, perforándolos o dando nacimiento a los aneurismas valvulares o murales. La friabilidadi de los trombos explica las frecuentes embolías que ocasionan abscesos o infartos sépticos en diferentes órganos. No son raras las embolf́as pulmonares cuando está comprometido el corazón de. recho.

El comienzo de esta enfermedad generalmente está enmascarado por enfermedad séptica, de la cual la endocarditis es una parte, o bien estalla bruscamente con un cuadro toxiinfeccioso grave. Debico a su curso casi fulminante, los signos son menos marcados que en la forma subaguda. Pueden hallarse los sintomas de una infección grave, en que los signos cardiacos pasan inadvertidos, sea porque la auscultáción no es muy fructífera o porque el corazón es silencioso, debido a la localización parietal de la endocarditis. La rápida evolu. ción de la enfermedad hace que la anemia, la esplenomegalia. las dedes hipocráticos y los síntomas de falla cardiaca, apenas se esbocen. 


\section{Endocarditis bacteriana sub-aguda.}

Llamada también endocarditis ulcerativa crónica, endccarditís úlcero-vegetante, encocarditis maligna, endocarditis lenta o sepsis lenta, fué descrita en forma magistral por Jaccoud en 1882 y completada por W. Osler (Goulstonian Lectures) en 1885. Sin embargo la primera descripción olínica de eeta enfermedad 'fué hecha por Senhouse Kirkes en 1854. al describir las embolías en las endocarditis. y un año más tarde Rokitansky señala las ulceraciones valvulares en un enfermo con un cuadto infeccioso atipico. Pero si nueremos ser justicieros, debemos citar a J. M. Lancisi quien en 1707 en su obra "De subitaneis mortibus" se refiere a este cuadro. A Corvisart y Leroux iquienes en 1801 en su "Tratado de las enfermedades del corazón y de los grandes vasos", describen las Fegetaciones en las válvulas y en la parad de la aurícula, que corresponden a las que se encuentran en la endocarditis bacteriana subaguda. Y fué después de los trabajos je Lancereaux in 1862 y de Weife en 1870 que se incluyó esta enfermedad como una entidad clínica en la patología. Harbitz y Litten, en 1899 , se encargan de dar luz a la anatomía patológica y a la historia de este cuadro morboso. H. Lenhartz en su obra "Die septischen Erḱrankungen " describe los estafilococos, los neumococos y los gonococos, como organismos causantes de la "endocarditis séptica". En 1903, Schottmüller, desiribe el estrectococo viridans como agente causal en el $80 \%$ a $90 \%$ de los casos.

En el niño le cupo a Bouchut, en 1869, hacer la primera descripción clínica de esta enfermedad, al relatar las alteraciones patológicas encontradas en un niño de 8 años, muerto a consecuencias de una embolía cerebral.

\section{Frecuencia.}

Revisando la literatura mundial, en 1904, Weil logra reunir 26 casos de endocarditis bacteriana subaguda en niños. Rost y Fischer, recopilando casuistica de los últimos 50 años hasta 1928 , obtienen 64 casos, a los que agregan 12 obs:r. vaciones de su cosecha personal hecha en 11 años (1917. 1928). M. Acuña y A. Puglisi, en 1936, publican 7 casos, que reúnen después de 15 años. Segers. Monserrat y otros. en 1939, recorriendo toda la literatura pediátrica argentina. recopilan 15 casos, a los que agregan 2 observaciones perso. nales. 
En nuestro país, las observaciones en adultos son regularmente numerosas, asi Prado Tagle, en 1925, publica 12 casos, Garretón Silva, en 1934, estudia 85 casos. Las observaciones publicadas en niños son sorprendentemente escasas. En 1930 Daneri publica 2 observaciones, en 1925, Intante Yavar describe 1 caso.

Nuestra serie está compuesta de 10 observaciones. que incluye el caso de Infante, reunidas en 7 años (1934-1941) entre los enfetmos del Hospital Clínico de Niños "Roberto del Río".

Como se ve en esta enfermedad si bien es poco frecuente, está muy lejos de constituir una rareza en la infancia. Su frecuencia en el niño sería de un $10 \%$, según Horder, deducido de su serie de 88 casos que incluye adultos y niños. M. G. Wilson en una serie de 13 casos, cuyas ledades fluctuaban entre 9 y 30 años, encuentra 3 casos menores de 15 años.

Si estudiamos el porcentaje de la endocarditis bacteriara subaguda en relación a las carditis reumáticas y ambas las relacionamos con el número de nínos hospitalizados en el Servicio de Medicina Interna, por enfermedades propias de la segunda y tercera infancias, exceptuando la ruberculosis $y$ las enfermedades infecto-contagiosas, tenemos (Tabla I).

\section{TABLA I}

Relación de la enódocanditis bacteriana sub-aguda con ta cardítis reumática.

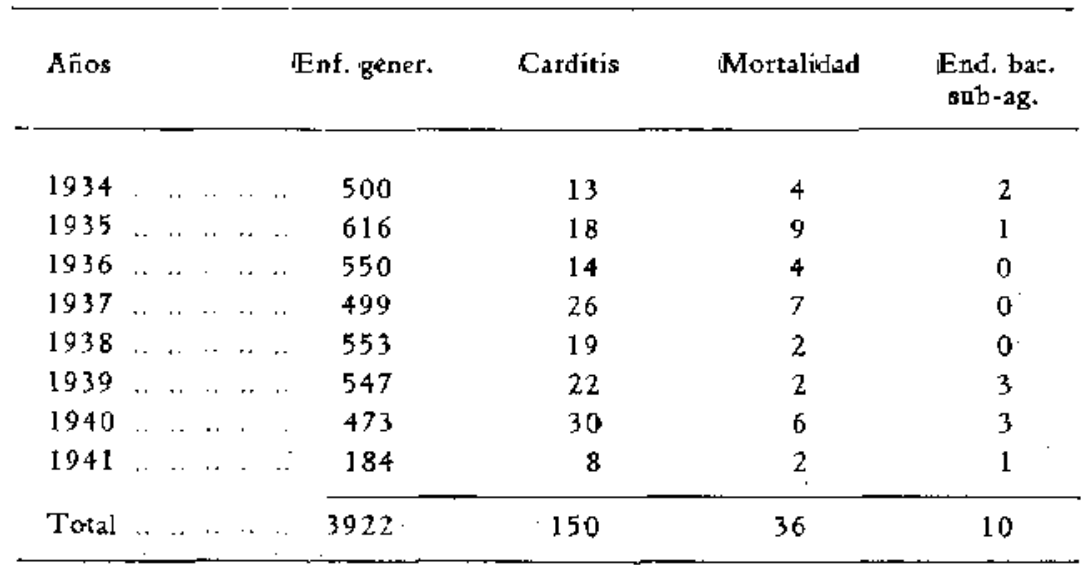

(*) E1 cómputo se ba becbo hasta V-41. 
Del examen del cuadro se deduce que el problema de la endocarditis bacteriana subaguda en la infancia, es de mayor importancia que lo que aparentemente pudiera creerse. Pot cada 150 endocarditis reumáticas, existen 10 endocarditis bacteriana subaguda, es decir, que hay una proporción de 15 : 1. Pero es mucho más grave si reparamos en el diferentz pronóstico que estas cardiopatías tienen, mientras una es compatible, en la mayoría de los casos, con una sobrevida más o menos prolongada, la otra lleva irremisiblemente a la muerte a plazo más o menos corto. De 46 muertes por endocarditis valvalar, 10 lo hacen en forma de endocarditis bactetiana subaguda, lo que da una proporción de $3,6: 11$.

Al examinar la frecuencia por edad, lo haremos tam. bién en relación a la endocarditis causada por la enfermedad reumática.

\section{TABLA II}

Frecuencia por edad de la yendocsirditis bacteriana sub-aguda en relación con la endocarditis reumatica.

\begin{tabular}{|c|c|c|c|c|c|c|c|c|c|c|}
\hline Edad ré & años & 5 & 6 & 7 & 8 & 9 & 10 & 11 & 12 & 13 \\
\hline Endoxarditis & $N \cdot{ }^{\circ}$ de casos & 17 & 17 & 21 & 28 & 23 & 23 & 20 & 17 & 4 \\
\hline rumáticas * & $\%$ & 84 & 80 & 94 & 68 & 65 & 64 & 62 & 40 & 20 \\
\hline $\begin{array}{l}\text { Endocarditis } \\
\text { bacteriana }\end{array}$ & $\begin{array}{l}83 \text { casos } \\
\text { de liter. }\end{array}$ & 5 & $?$ & 8 & 12 & 9 & 9 & 20 & 11 & 6 \\
\hline sub-agoda & Serie auestri & 0 & 0 & 1 & 2 & 3 & 2 & 0 & 1 & 1 \\
\hline
\end{tabular}

(*) iN. de casos y \% de endoc. reumát. sîcuela del primer ataque de poljartrítis (De la tesis del Dr. A. Saavedra).

El número de casos de endocarditis reumática, por años de edad, va en aumento, alcanzando las mayores cifras entre 10 8 y 11 años; ocurte lo inverso por el porcentaje de compromiso cardíaco en relación al número de reumáticos, el porcentaje disminuye a medida que avanza la edad. La edad más propicia para el desarrollo de la endocarditis bacteriana subaguda está entre los 8 y 12 años. En la serie recogida de la literatura, al igual que en la nuestra, no se encuentra ningún caso por debajo de los 5 años. Los casos relatados antes de esta edad, a menos que sean probados por la anatomía pa. 
tológica, deben ser analizados muy bien. $Y$ no es improbable que sean similares a los casos descritos por Lewis y Grant. de niños con cardiopatía congénita que a su muerte se encontró una endocarditis infecciosa aguda.

\section{Etiología.}

El curso más o menos acelerado o retardado que la endocarditís bacteriana subaguda puede tener, está subordinado con mucho, a la mayor o menor virulencia del germen causal. Los autores están acordes en considerar que ell microorganismo encontrado más comúnmente en este tipo de endocarditis es el estreptococo viridans. Christian de 117 casos de endo. carditis bacteriana subaguda con bemocultivo positivo, encontró que 150 casos etan debidos a este agente. Quedaría no más de un $5 \%$ a un $10 \%$ para ex estafilococo, el bacilus influenzae, el neumococo, el gonococo, el meningococo, el bacilus coli y otros de menor frecuencia.

En nuestra serie de 10 casos, desgraciadamente hemos estado poco afortunados. De 6 casos en que se hizo el hemocultivo, a pesar de que en dos de ellos se practicó en dos ocasiones, sólo en uno (Caso 5) obtuvimos el desarrollo del estreptococo no-hemolítico. La explicación debe estar, más que en un defecto de los medios de cultivo, en el escaso número de muestras de sangre que se envió al laboratorio, ocastonado a su vez por los pocos días que algunos de estos en f'rmos permanecieron en el hospital, ya que es poco probable que casi todos hubiesen estado en el período libre de bac. terias (ibacteria-free stage, Libman).

\section{Patogenia.}

Los factores que determinan el desarrollo de la endocarditis bacteriana subaguda, los podemos agrupar como si gue: 1. Presencia de una alteración anatómica del corazón, aćlquirida o congénita: 2. Presencia de trombos en la superficie endocárdica: 3. Presencia de microortganismos en la san. gre; y 4 . Cierta reacción inmunológica del organismo frente a los agentes microbianos.

La endocarditis bacteriana subaguda se implanta en corazones anteriormente dañados por el reumatismo en un $75 \%$ a $90 \%$ de los casos, a lo que hay que agregar cierto número que lo hace sobre una cardiopatía congénita o de otro origen. En el porcentaje restante el agente mictobiano se instala en 
un corazón aparentemente sano; en este caso la infección es causada, seguramente, por microorganismos más virulentos.

Los niños más expuestos al desarrollo de este tipo de endocarditis bacteriana, son aquellos cuya lesión cardíaca no es intensa y acasiona muy poca o ninguna molestia, que no tienen o han teriido sintomas de insuficiencia cardiaca y que no han sufrido ataques repetidos de reumatismo. Es raro cuando la infección reumática se ha manifestado en forma de corea o cuando existe fibrilación auricular o hipertensión. A tótos los autores les ha llamado la atención, que el corazón en el cual se implanta una endocarditis bacteriana subaguda. aparte de su alteración endocárdica generalmente valvular; jebe efectuar su trabajo en buenas condiciones. Personalmente, se me ocurre, que para que en el endocardio alterado prendan gérmenes de escasa virulencia, es necesario, aparte de una buena vascularización de la válvula, que, y esto debe ser de la mayor importancia, la circulación de la sangra sé haga en condiciones normales por estos vasos de nueva formación. Los ataques repetidos de reumatismo, con su secuela anatómica, la cicatriz perivascular, la arteritis $y$ aun $l_{a}$ endarteritis obliterante, acarrean una dificultad en la citculación sanguínea de la válvula. Efecto análogo tendría la insuficiencia cardíaca.

En nuestros casos, hubo antecedentes precisos de ataque de poliartritis réumática en 4 de ellos (casos $7,8,9$ y 10), en 2 una pousée y en el texcero una recrudescencia de carditis y en el cuarto de artritis. De los 6 restantes, en 4 hubo antecedentes de dolores articulares, en 1 (caso 2) sin historia reumática, la cardiopatía se instaló a raíz de una neumonía y en el último (caso 1) no hay antecedentes precisos. Como vemos. la mayoría no tiene una clara historia de reumatismo, hecho que no debe sorprendernos, ya que buen número de veces, una tonsilitis, un cuadro gripal inocente, o dolores articulares leves, feriódicos, pasa jeros, que el niño o sus familiares no valorizan debidamente y, por ende. lo olvidan, no son más que el ropaje con que la infección reumática se enmascara en esta edad de la vida. En ninguno de los casos hubo ataques de corea $o$ de asistolia.

Las personas más vulnerables a la endocarditis bacteriana sub-aguda son aquellas con liesión aórtica, aislada o más comúnmente en combinación con la endocarditis mitral. En discrepancia con este modo de pensar, se encuentra Blumer que da un $58 \%$ de mitrálicos. Garretón Silva $78 \%$; Wilson. $84 \%$. Observando el cuadro que insertamos a continuación. 
vemos que son los aórticos y mitroaórticos, los más expuestos a hacer una endocarditis bacteriana sub-aguda.

TABLA III

Endocarditis reumáticas más susceptibles de desarrollar una et:focarditis bacteriana |sib-aguda,

\begin{tabular}{|c|c|c|c|}
\hline Tipo de endocarditis & Mirtal & Mitrobóntico & Aórtico \\
\hline 209 casos de crd. reumit. .. .. .. & $\begin{array}{c}190 \\
(91 \%)\end{array}$ & $\begin{array}{c}18 \\
(8.6 \%)\end{array}$ & $\begin{array}{c}3 \\
(0.4 \%)\end{array}$ \\
\hline Endoc, bact, sub-aguda .. .. .. : & $\begin{array}{c}5 \\
(50 \%)\end{array}$ & $\begin{array}{c}4 \\
(40 \%)\end{array}$ & $\begin{array}{c}1 \\
(10 \%)\end{array}$ \\
\hline
\end{tabular}

Entonces, de nuestros casos, 5 lo hicieron sobre una lesión mitral (50:\%), y 5 en una endocarditis aórtica $o$ mitroaórtica (50\%). Pero no es esto precisamente lo que queremos demostrar. sino cuál es la expectativa que tiene un mitrálico y un mitraórtico de caer en una endocarditis bactcriana sub-aguda, y relacionando el número y tipo de endocarditis reumática con el número y tipo de endocarditis bacteriana sub-aguda. tenemos que: en el $2.63 \%$ una endocarditis mitrálica es susceptible de hacer una endocarditis séptica sub-aguda, este porcentaje aumenta a $22,2 \%$ si es mitroaórtico y aun más, si es aórtico puro. Ordenando según esto las lesiones valvulares reumáticas, en las que se observa más frecuentemente la endocarditis bacteriana sub-aguda, quedaría así:

1. Insuficiencia aórtica.

2. Insuficiencia mitroaórtica.

3. Estrechez mitral.

- 4. Insuficiencia tricuspidea.

En nuestra serie no se observó la cardiopatía congénita como factor predisponente, que se encontraria en el siguiente orden:

1. Vályulas aórticas bicúspides.

2. Persistencia del conducto arteriovenoso de Botal.

3. Estrechez aórtica.

4. Estrechez surb-aórtica.

5. Comunicación interventricular. 
De estos 4 tipos de cardiopatía congénita, el que está destinado a desaparecer como causa predisponente, dados los espléndidos resultados que se obtienen con la intervención quirúrgica, es la persistencia del conducto arterio-venoso, iOjalá algún procedimiento similar se pudiera emplear con la endocarditis reumática!

En cuanto a la causa determinante de la formación del trombo plaqueto-fibrinoso en el endocardio, nos estrellamos con la eterna discusión de que para algunos, los miçroorganiomos invadirian la válvula desde la superficie, y para otros, los más, el endocardio sería infectado por embolía bacteriana de los capilares valvulares. El trombo plaqueto-fíbrinoso recién formado es pobre en leucocitos y tendría la función de localizar la bacteriemia, dado el espléndido medio de cultivo constituído por la fibrina y si a esto agregamos la pobreza en leucocitos, tenemos que los agentes microbianos se encuentran en inmejorables condiciones para su proliferación.

Es condición indispensable, entonces, la presencia de una bacteriemia transitoria, cuya puerta de entrada no siempre es posible descubrir. A menudo las infecciones del árbol respiratorio superior, o pequeñas intervenciones quirúrgicas, como la extracción de dientes o tonsilas, son circunstancias que se suelen acompañar de bacteriemias y pueden ser el medio por el cual los agentes microbianos ganan acceso a las válvulas cardiacas.

Se ha demostrado experimentalmente, que para obtener una endocarditis bacteriana del tipo sub-agudo, además del daño endocarditis y de la bacteriemia, es condición indispensable que el organismo ofrezca cierta resistencia, por medio de anticuerpos, al desarrollo del germen.

La bacteriemia primitiva, la causante de la endocarditis bacteriana sub-aguda, es transitoria, desaparece más o menos rápidamente, porque es destruída por los anticuerpos sanguíneos y por los leucocitos. A ella sigue la bacteriemia que tiene su origen en el trombo valvular infectado. Una demostración de este hecho es la observación de Hemman y Reinhoff. de una septicemia sub-aguda a estreptococo viridans, en la que obtuvo la curación definitiva por la extirpación de un aneurisma arterio-venoso de la arteria y venas ilíaca externa; el alejamiento de los trombos infectados que contenia el aneurisma extraído, acarreó la completa desaparición de los agentes microbianos de la sangre y la mejoría. 


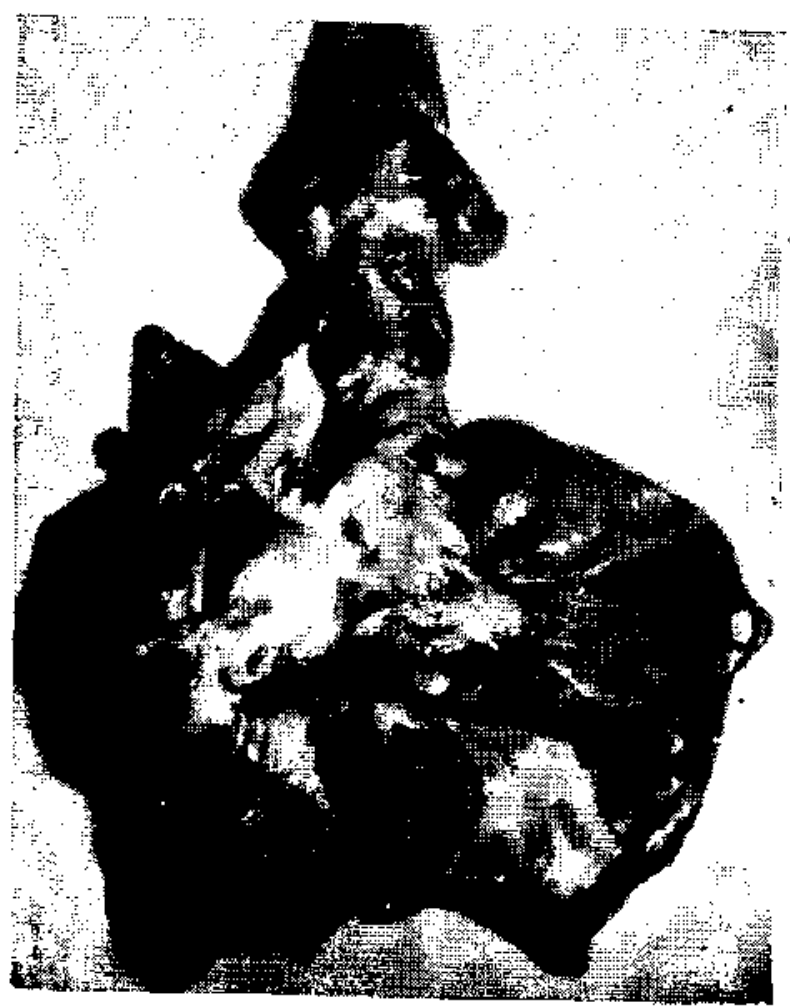

RUPTUR:A DE LA AORTA

(Var Caso Ni? 10. Autopsia 85-4I).

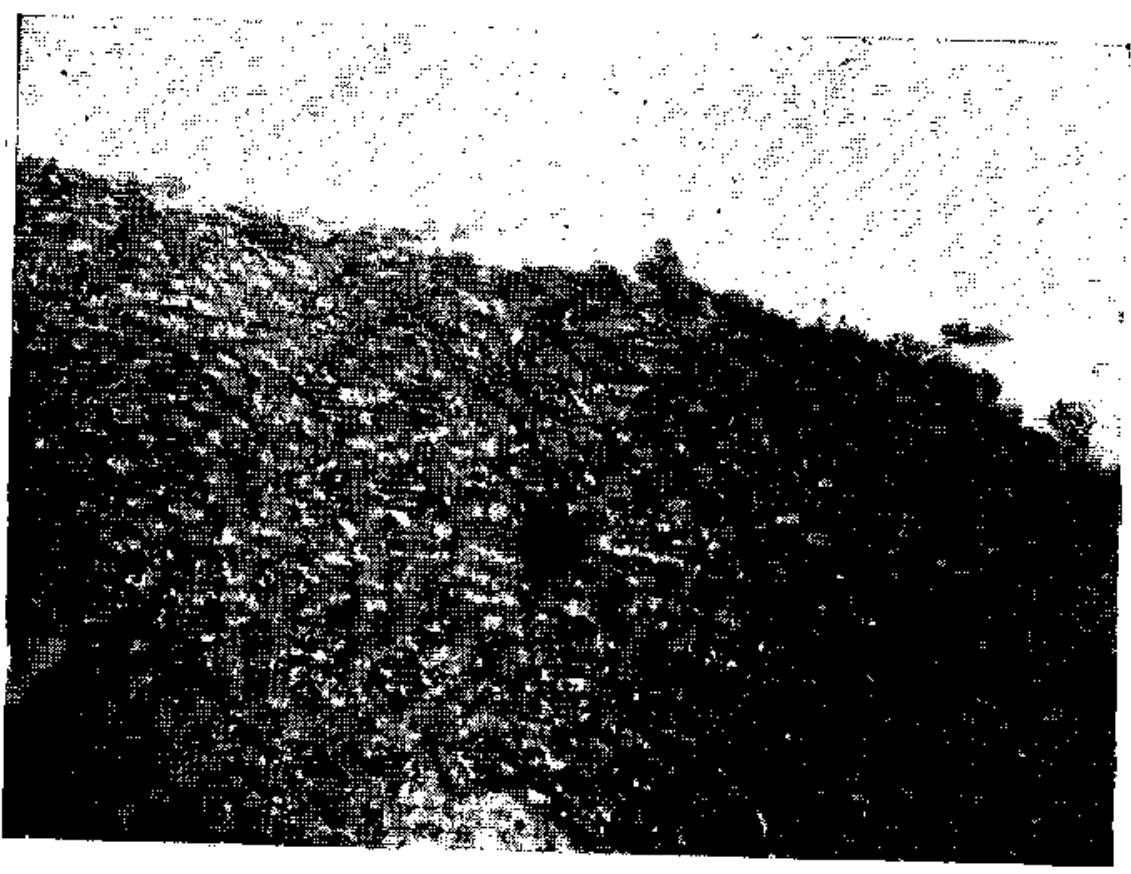

NECROBIOSIS I: LA PARED ACRTICA 


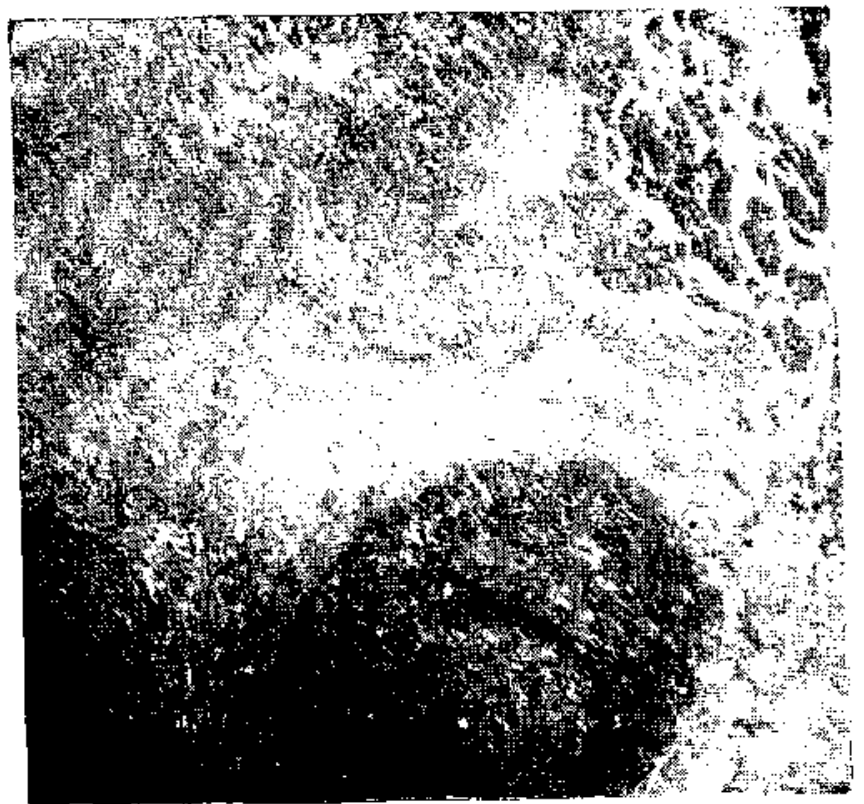

VASO TRCLMBOSADO CEI, NACIMLENTO DE LA AORTA

(V.ar Caso Na 10 . Autopsia N.785-41).

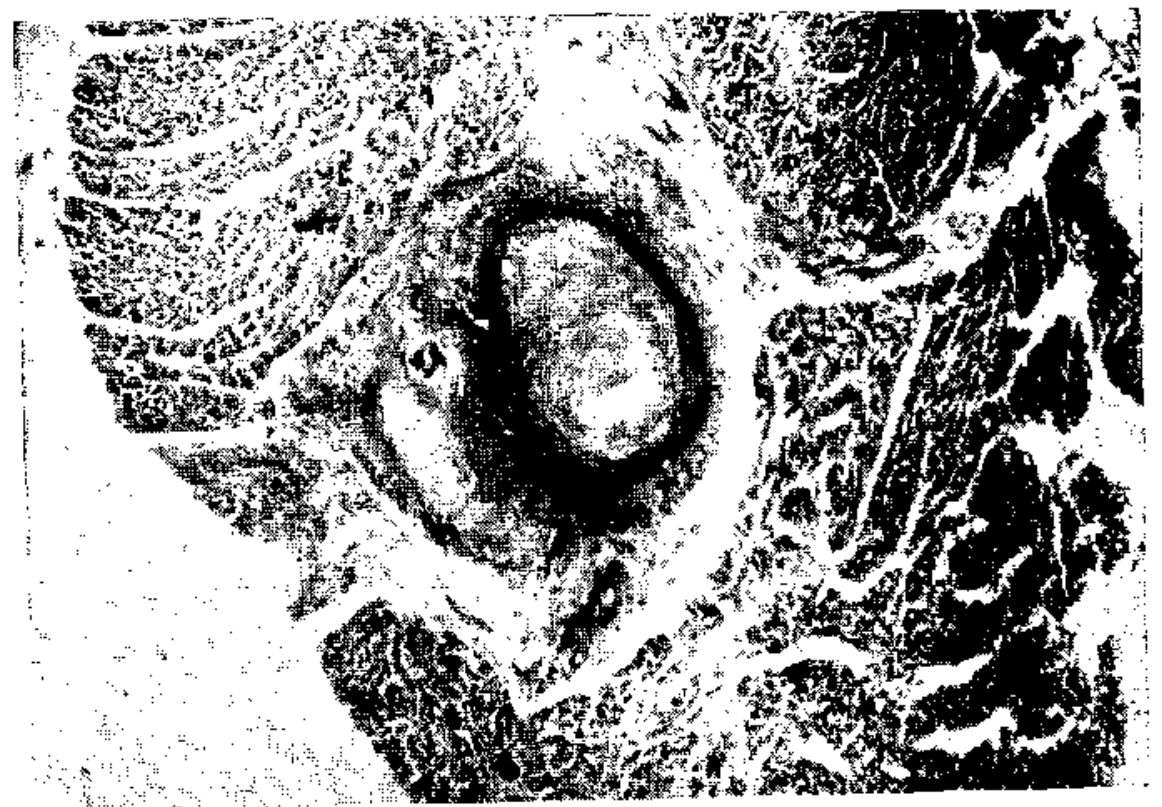

NECROBICSIS DF: LA PARED AORTICA.

(Ver caso N. $\left.{ }^{*} 10\right)$. 


\section{Cuadro clínico.}

En general, los sintomas de una toxemia generaimente leve, intensa en algunos casos, los signos embólicos, la pressncia de una cardiopatía valvular y el hallazgo del agente microbiano en la sangre, bastan para el diagnóstico.

La toxemia leve, como corresponde a un agente de escasa virulencia, se manifiesta por sintomas muy diversos, tales como malestar general, astenia, anorexia, náuseas o vómitos. pérdida de peso, dolores articulares o musculares. Es en este perícdo cuando pensamos en una tifoídea o en una enfermedad reumática. aunque fa temperatura, los escalofríos. la esplenomegalia y los signos embólicos (hematuria, petequias, cerebrales, etc.), nos harán rectificar nuestro diagnóstico. La pérdida de peso y el grado de anemia serían más intensas que en la carditis aguda reumática.

El alza de temperatura no constituiría una regla, tenemos algunos casos en que no se presentó o duró uno o dos días. En ocasiones es de tipo séptico, en otras de tipo continuo o más a menudo alternan períodos febriles con períodos apiréticos, aunque esto sería menos frecuente en el niño que en el adulto.

La esplenomegalia es uno de los signos más constantes. En nuestra serie fué posible comprobarlo clínicamente en casi todos los casos. En dos de ellos, el bazo no se palpó en vida, pero a la autopsia el aumento fué indiscutible. Se palpó con dificultad en dos niños, en el reborde lo encontramos en dos ocasiones, y se presentó una gran esplenomegalia en 4 , a. 2 , 3,4 y 6 traveses de dedo del reborde costal: en dos de éstos hubo manifestaciones de infarto esplénico durante la evolución de su enfermedad en el servicio.

Pero son los sintomas externos, visibles, acompañados o no de dolor lo que hizo que nuestros niños acudieran al hospital. En 4 casos (N.os 2, 3, 5 y 7), fué la hemiplegia; en dos (N.os 4 y 10), la temperatura y compromiso articular doloroso; en dos (N.os 6 y 9), la hematuria y edemas; en uno (N. ${ }^{8}$ ), la intensa toxemia y finalmente en el caso N. 1 . seguramente por síntomas cardio-vasculares.

Las petequias, fenómenos embólicos de la piel o de las mucosas, se presentan especialmente en la región axilar y base del cuello, en la mucosa bucal o conjuntiva. Petequias en la parte superior del tórax, cuello y velo del paladar hubo en dos (casos N.os 5 y 8), en uno se localizaron en la cara in- 
terna del brazo izquierdo, duraron 7 días para reaparecer en el dorso a los 3 días (caso N."2), petequias diseminadas sin distribución especial en el caso $N^{\circ}{ }^{\circ}$; en el caso N. ${ }^{\circ} 7$ se encontraron elementos pápulo-eritematosos en las extremidades; pequeñas equimosis en la cara interna de la pierna izquierda en el caso N. 10 . En la conjuntiva no las observamos. Estuvo también ausente el signo de Osler, con su localización clásica en las eminencias palmares o pulpejo de los dedos u ortejos. Por lo demás, es necesario una larga evolución, propiamente lenta, para que la endoteliosis haga presente este signo.

De tanta constancia como la esplenomegalia, fué la hematuria microscópica, en un caso (N.:9), macroscópica correspondiente a una nefritis terminal. La cilindruria se observó en 5 niños.

No buscamos con interés especial la retinitis embólica, signo de gran importancia en algunos casos. Aparte de los 4 casos que ingresaton con sintomas cerebrales, 3 más presentaron este cuadro dụrante sn hospitalización. Infarto pulmonar e ictericia, dependientes más bien del compromiso del corazón derecho no se observó. Dedos hipocráticos de III grado, en dos casos, de I y II grados en 3 .

Antes de terminar esta breve reseña sobre la sintomatología embólica, debemos mencionar el daño que esta enfermedad puede ocasionar en los vasos de grueso calibre como la aorta sea porque el proceso necrótico se propaga desde las válvulas aórticas, sea porque en ella se localice la infección séptica, en ambos casos el proceso puede llegar a la producción de un aneurisma y aun a la ruptura de la arteria. Peto existe otro mecanismo de producción de este daño vascular. me refiero a la necrosis isquémica, aséptica, de la pared aórtica, producida por embolía o más bien por endotelitis de los vasa-vasorum. En este caso, a diferencia del anterior, en el examen histopatológico, no se encuentran alteraciones inflamatorias en los bordes de la ruptura del vaso. Las fotografías que se insertan corresponden al caso $\mathrm{N}: 010$, que presentó un accidente de este tipo.

El cuadro sanguíneo, como se sabe, no tiene nada característico. La velocidad de sectimentación de los hematíes está acelerada en mayor o menor grado, lo que correspondería a una mayor o menor actividad del proceso séptico endocárdico. En nuestros casos osciló entre $27 \mathrm{~mm}$. y $100 \mathrm{~mm}$. en 1 hr. (término medio, $55 \mathrm{~mm}$.). En el hemograma hay generalmente una anemia secundaria, que en nuestros enfermos 
osciló entre $3 \frac{1}{2}$ y 4 millones, con una hemoglobina de 10 a 12 grs, por ciento, a excepción de un caso en que hubo und oligocitemia de $1.640,000$ y una oligocromemia de 6 grs. \%. Existe una leucocitosis de mediana intensidad, aunque no son: raras las cifras extremas, caso N. 5 con 6.300 leucocitos por nnm 3 , caso N." 8 con 40,000 , el término medio obtenido fué de 17,600 leucocitos por $\mathrm{mm} 3$. En la fórmula blanca se presentó una neutrofilia qué varió entre $65 \%$ y $94 \%$, siti apreciarse una reacción especialmente marcada de parte de los mónocitos. Las células endoteliales, en los casos en que se investigó no se encontraron.

El diagnóstico de esta enfermedad no siempre es sencillo, por lo cual debemos tenerla siemprie presente ante una cardiopatía valvular 0 "congénita, $y$ si a esto agregamios síntcmas tóxicos y embólicos, el diagnóstico se hace más probable: Más difícil es cuando la endocarditis es parietal y no da sigros auscultatorios al comienzo, pero que generalmente aparecen si el paciente scbrevive 6 a 8 semanas. Es en estos cascs cuando el hallazgo del agente causal se hace indispensable para el diagnóstico. 'Estas contingencias ban hecho que Libman describa varias formas de endocarditis: los casos típicos con hemocultivo positivo: casos con hemocultivo negativo. pero clínicamente iguales a los anteriores y que a la autopsia tienen bacterias en las verrucocidades; pacientes cuya fiebre $\mathrm{v}$ sintomas mejoran y que a la autopsia se encuentran pocas bacterias en las verrucocidades; pacientes en los que la fiebre no es un síntoma característico y que a la autopsia muestra organización con o sin calcificación y evidencia de lesiones cmbólicas renales (es en estos en que se encuentra más co. múnmente la falla cardíaca y la fibrilación auricular).

\section{Duración y terminación.}

La duración de esta enfermedad es variable, dependicndo tanto de la virulencia del germen causal, como d? las condiciones generales del paciente. Por otra parte el comienzo generalmentiz insicioso, hace imposible la determinación aproximada de la fecha de comienzo, la que sería etrado relacicnarla con la aparición de los síntomas por los cuales los enfermos concurren al hospital. ya que comúnmente son de orden embólico, que como sabemos, no se presentan precisamente al comienzo de la endocarditis. Las frecuentes remisiones por meses y aun años, hace más difícil poder determinar en un momento dado la duración de la enfermedad (véase caso N. 9 ). 
En la observación N. 5 hay hasta ahora una sobrevida de $21 / 2$ años, único caso de hemocultivo positivo (estreptococo nohemolítico). Los hallazgos de autopsia de nuestros casos, en que al lado de lesiones embólicas recientes, existen infar. tos antiguos, apoyan nuestra aseveración de que la evolución cie la enfiermiedad es mayor que la que se podría deducir por la estadía en el hospital.

La mejoría espontánea de la endocarditis bacteriana subaguda es una terminación muy poco frecuente, para Libman se presentaría en el $3 \%$ de los casos.

La causa de muerte en la mayoría de los casos es por embolia cerebral, en segundo término por insuficiencia car díaca. En nuestra serie, se practicó la autopsia en 6 , en 3 había embolias recientes cerebrales (casos N." 1,2 y 3), en el caso 1 se agregó una gran bemorralgia del bemisferio derecho, y el caso N." 4 que falleció a consecuencias de la lesión cerebral embólica, pero que no sa practicó la autopsia. La observación N.:9, que falleció con una nefritis crónica, a la necropsia se enccntró una gran cavidad en el lóbulo occipi[a] izquierdo. El N.9 10, por ruptura de la aorta y hemopericardio; el $\mathrm{N} .8$, por síntomas toxémico-embólicos; el N. ${ }^{7}$. retirado por la familia en insuficiencia cardíaca, fallece al día siguiente.

\section{Reseña znátomopatológica.}

En los 6 casos en que se practicó la necropsia, se encontró la endocarditis úlcero-vegetante propia de esta enfermedad. En unos predominaba el proceso necrosante, en otros la organización se halló bastante avanzada. Signos embólicos en la totalidad. Encefálicos en 4, infarto espléndido en 3 . renal en 5 . El aumento del bazo fué constante, el peso varió entre 92 grs. y 440 grs., término medio 230 grs.

E1 proceso séptico atacó a la válvula mitral en 5 casos, en 2 hubo compromiso concomitante de la aorta, en el 6 .? la endocarditis bacteriana prendió en la única válvula anteriotmente dañada, la aórtica. La determinación histopatológica de la naturaleza de la endocarditis antigua, primitiva, no siempre es fácil. El clásico nódulo de Ascherfif se encontró en una sola ocasión, lo que indudablemente corresponde a dos precesos en evolución, el reumático y el séptico. El hallazgo de la cicatriz perivascular, junto a los antecedentes der enfermo, nos hacen asegutar, en la mayoría de nuestros cascs, la etiología reumática de la endocarditis antigua. 


\section{Tratamierito.}

Hasta hace poco el tratamiento de la endocarditis bacteriana subaguda era de resultados infructuosos, lo que no significa que en la actualidad poseamos el procedimiento ideal de tratamiento: pero la literatura nos relata éxitos en ocasiones sorprendentes con la administración de las sulfanilamidas solas o mejor en combinación con otros procedimientos. que en resumen tienden a facilitar o aumentar la acción de la quimioterapia. Me limitaré solamenta a dar los resultados que se han obtenido, para mayores detalles remito a los lectores a la bibliografía pertinente.

De 200 casos de endocarditis bacteriana subaguda o a estreptococo viridans, tratados con sulfonamidas (sulfanilamida, sulfopiridina, sulforhiazol), 12 mejoraton, lo que da un $6 \%$.

En 43 casos la quimioterapia se combinó con la heparina, mejoraron 5, es decir el $11 \frac{1}{2} \%$.

En 24 casos, a la quimioterapia se agregó la hipertermía física, lo que dió una mejoría en 4 . o sea un $16 \%$.

De 21 enfermos tratados con sulfonamidas en combinación ecn hipertermia producida por inyección endorsnosa de vacuna tífica-paratífica, mejoraron 5 , lo que bace un $25 \%$.

La acción que los preparados sulfonamídicos tienen sobre los gérmenes circulantes, no se observa con la misma intensidad sobre los microorganismos más o menos encastiliados en los trombos endocárdicos. De ahí que sea necesario facilitat la acción ce la quimioterapia, sea impidiendo nuevos depósitos de fibrina en la válvula (heparina), sea aumentando la acción bactericida (100 veces según White) de la sulfonamidas (hipertermia). Uno y otro procedimien. to tienen sus inconvenientes; nuestra experiencia es nula, no opinamos sobre la efectividad de este nuevo procedimiento terapéuti:o.

\section{OBSERVACIONES}

CASO N.9 1.-Julio Z.-13 años. Bol, 6298. Ingresa el 21-VII-34.

Artecadentes: La historia clinica de ste niño, desgraciadiamente se ha extraviado. de tal marera que los datos que anotenos de stu sintomatologia que tuvo en vida. es extraída del relato hecho por los mêdicos que lo atendieror

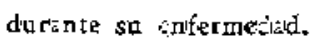

Ingréó con la sintomatología de ana insuficiencia tóotica, que fué diagnosticada como reumárica, a pesar de no existir. pintecodente alguno de sintomas atticulates thi cardii-cos anteriones. Se trata con salicilato de sodio a a'tas dosis. Pronto se repone y comienza a kvantarse. 
Brugeamente, y sin mediar causa que lo explicara, al dia 10-VIrI-34, a las 13 horas, cae con an ataque tónico-clónico, del fall no se recupera y failléte.

Autopsia: Endocardiris crónica fábrosa de los velos aćrticos y endocarditis ń1wro-vegetante recurrente. Fonma septicíníca; bazo pesó 270 grs.. de consistencia blanda. Riñones cianóticos. Infüto embóitico antiguo en la parte interior del riñón desecho. Higado cianótico pesó 1,260 grs.

Foco de encefaltis ambólica situado en al trmisferio denodho por fuera de los grandes núcleos y gran Oxemorragia reciente concomitante.

Páncreas, 72 grs. Cuerpo tiroidis, 14 grs. Timo, 17 grs. Supracrena. les. 7 ges. cakda una.

CASO N.9 2.- (Puilicado por el Dr. R. Infante Yavar. Arch. Hosp. R. del Rio. 1935). María C.: 9 años. Bol. No 7285. Ingresa el 28-XI-34.

Antecedentes: Padre falleció de aptadicitis. Midre sin Wass. Un herm:no que es sano. Sarampión en la primen infancia. Ha sufrido de dolores articulates, expicialmente en invierno, se le hir:chaba unil todilla, no sabe precisar cuál. Extraodmatia dienza con los juegos.

Enfermedad actual: Comienza 27 dias antes (el 1.9-XI-34), con fiebre alta, de $38^{\circ}$ y $39^{\circ}$. vómitos a rias mucozas. sin sangrz, anorexia $y$ adinamia muy marcata. El cuadro descrito se mantuvo sin variación hista el $26-\mathrm{XI}$, en que tiene brusimante pérdida dil conotimiento, contracciones tónico--lónicas generallizadas y. telajación exrinreriana. Despás quedó en un evitado soporoso y se manifiesta una parálisis fact: 1 infenior detecha, del miembro superior dercotho y afasia motora.

Examen fincico: Niña en posición pasiva, pálida, tomp. 381/2\% respiraciones 26, susorio lúcido. Piel: Manchas pigmentadas como leatejas en todo el cuerpo. Petequias en la axi'ia izquierda. Ligero enfriaminto de bu extremidad superior izquierda. Hóperesteja. Raya metingea positiva. Cara: Parálisis facial deracha de tipo central. Dentadura incompleta y an mal extado. Faringe $y$ amigdąlas nommales.' Oidos nada especial. Cuello: Discretra rigidez de la nota. Tórax: Respiración soplante en la region hiliar. Sistema cardio-vascular: Pulso radial derecho 148, regular; radial izquierdo blando, difícil de palpar, Presión H. D. $12 \frac{1}{2} \times 8 \frac{1}{2}$ (Vaçuez), H. I. no se aprecia ascilación. Corazón: Punta se ve y s: palpa for fuera del mamshón. Frea de macidzz cardiaca aumentada. Fremita sístólico de la punta. Doble soplo de la punta propagado a la axila. Abdomen: Higado a 2 trave:es del rebonde costal. Bazo so palpix a $35 / 2$ traveses del riborde. algo dinro, indoloro. Región anogenital: Nalda de opecial. Extremidades: Flacidez e imporencia funcional del miambro superior deteoho. Ligrro enfriamiento de la superior izquierda. Dados hipokráticos de tercer grado. Disminuctión de las fuerzas en el miembro inficrior deretho con conservación de los movimientos. Reflejos rotalianos exaltados, más a detecha. Clonus discreto. Babinsikly espontáneo a izquierda.

Evolución y tratamiento: Se dejan tónicos cardiovacculares y medidas higiénicas. Tranefusiones sanguineas en.número de 3 te 20.60 y $80 \mathrm{ec}$. R. Wi- 
dal, paratifus A y B y de Weil Félix negativas. R. Wass, nggativa, R. Kabn dudosa. Orina: Densidad, 1020; acetona', indicios; albúmina, indicios; g!óbulos blancos y rojos. eiveasos.

Hemograma (30-XI-34): Hematíes, 3.540,000. Leucositos, 22,500.

$\begin{array}{cccccccc}\text { bas. } & \text { cos. } & \text { mie. } & \text { juv. } & \text { bas. } & \text { seg. } & \text { lin. } & \text { mor. } \\ \text { - } & - & - & 1 & 36 & 52 & 16 & 3\end{array}$

Sedimentación: $48 \mathrm{~mm}$, en una bora (Westengren).

Hemorultivo $\left(1 .{ }^{\circ}-\mathrm{XII}-34\right.$ y $\left.7-\mathrm{X} \cdot \mathrm{II}-34\right)$ : negarivos.

Durante los primeros 10 dias de hospitalización no expicimenta mejoria alguna. La temperatura oscia entre $39^{\circ} \mathrm{F}^{+} 40^{\circ}$, pulso 140 . Lat hemiplegia no Ee modifica: aparize edema del mimbro superior derecho. El bazo aumenta visiblemente de tamaño basta 6 traveses del reborde ieostal. El hígado a 2 traves:s. Desaparecen las petequitas axilares iakquizedas.

IEl 10-XIII-34, ja disnez aumenta a 50, el fulso a 150, más pálida. Exdema de ambos miembros derecbos. Rizaparecen elementos petrquiales en e] dorso. Higado a 3 traveses, endurecito. Bazo símpre enorme. Fallece.

Autopsia: Protocolo N. ${ }^{9} 172,1934$. Pulmones: No se tetracn. la superficie de corte de coloración rojiza, lisa. En la región donsal media de! lóbulo inforior izquierdo se encuentran adherencias a la pared costal, constatándose también a ene nivel an pequeño nodulito calcificado menos que lenticalar, se encuentran ganglios peribrónquicos en este pulmón con contenido cretáceo y calcáreo. Además, en ambas cayidades pleurales se encontró abundante líquido amarillo citrino. Corazón: Lixquido piricárdico considerablemente aumentado. Corazón aumentado de tamaño en estado diastólico. La pared del ventricalo izquierdo en el corte de la punta mide 9 Imim., el derecho $1 \frac{1}{2}$ mm. En la válvisla mitral si eqcuestra en forma cirounscrita un engrosamiento de su bords, hallandace a ese nivel engrojadas y acortadas las cuerdas tendineas de los músculos papivares: sobre sa parte engrosada sobresale una masa blanca amarillenta consistente, adherente. que tíne hasta el tamaño de una uva. También se encucntran al lado de éstas, pequeñas promintncias más pequeñías. El resto de las válwulas y corta nomales. En el miocardio se observan en algunos puntos foquitos grisáceos turbios miliares, epecialmente a nivel dell corte de la punta. Abdomen.: Higado grande, thiptrhemiado, pesó $1.167 \mathrm{grs}$. de saperficie de corte turbia. Bazo muy grande, pisó 440 grs. Pulpa esplénica blanda, se encuentras muy diseminados numerosos infartos superíniales embólicos de coloración blanko amarillenta de forma cuneifoume. Murcosa gástrica e intestinal !igeramente cianótica. Cerebco: Presenta la piamadre hiperhemiada. En la base las arterias silvianas están libres hasta las más firas ramificaciones que sé pueden segitit. El polo posterior del hemisferio izquierdo se cucuentra reblandecido, de coloración anarillenta. También se halla ligetamente reblandecida la parte anterior del lóbulo temporal. Examen dxal cerebro fjjado en formalina: Cortes 
multiples transversales $y$ verticales del kerebro. IEn el hamiferio cercbeal izquierdo, la parie alta posterior de la primera circunvalución frontal, se encontró a nivel de la sustancia blanca poco por detajo de la sustancia gris, un pequeño vaso trombosado; alrededor de este vaso aparece una pequefía zona grisáce más oscuta que contrasta con el resto de la sustancia cetebral amarillenta. Examenes histológicos: Cottes de miocardio: se compraba que en relación con algunos vasos existen trombosis. presentándose rya el depósito fibritzoso adherido a las paredes $y$ con penetración de tristiocitos y elemertos conjuntivos júvanes. Alrededor de los vasos también existe intensa prolifetación inflamateria que forma un manguito. Corte de válorata tomando la patte proliferante: se observa gran parte del tejido necrosado (masa proliferante) in en su superficic. depósitos frubrinosos. Estroma de la vảlvula infiltrada de leucokitos. E1 resto di la válvula engrosado. Diagnástico anátomopatológico: "Endocarditis cróni fubrosa vaivular y cordal mirrálica y endocarditis poliposa nexrótica localizała. Gran bazo de pulpa bianda, bartosa, con infartos dmbólicos múltiples cuneiformes superficiales. Infartos embólicos de ambos riñones. Miocarditis intersticial emibótica. Encefalitis embólica difusa. Trombosis varcular un la parte alta pos $\rightarrow$ terior de la primera circunvolución frontal izquierda".

\section{Dr. Alberto Gazmán.}

CASO N.9 3,-Joré G.: 10 años. Bol. N. 86?6. Ingresa el 11-V-35.

Antecedentes: Padress sano; Wass, negativo: 8 hijos, uno mn:rto en primit2 infantia de trastornos notritivos agudo, 5 . abortos provocados. Sarampión a los 3 años. A los 8 años neumonía de la base izquierda, al $5.0^{\circ}$ día de evolución de esta, comienza a oits: un soplo sistólico de la punta del corazón que se fué acentaando poco a poco. hasta hacer indudable el diagnóstico dz insuficiencia mitral. Posteriormente, el niño se sintió rnást o manos bien, hacia vida activa, sin experimentar molestias, En 1934 se practiza una amigdalectomía, rupa convalecencia se hizo sin complicaciores.

Enfermedad actual: Hace 20 dias sobteriane, bruscamente escalofríos, m3lestar general, fiebte alta. Este cuadro dura 3 dias, después de los cuales se favanta y valvi al colegio. Pero hace 8 dias siente nuevaminte fiebre, adinamia. cefalea, dolores abdomíales. délírío, vómitos. Tratado en sa casa. llama la atención la temperatura en agujas y embotamiento sensorial que aparas hase dos dias.

Examen físico: Niño cmbotado, pálido. temperatuta $41^{\circ}$. Cabeza: pupilas mióticas, facies peritonial. llengua seca. saburtal. Olor fétido del aliento. Palmones: nada de espcial. Sistema cardiovascular: Presión $11 \%$ × 6 . Soplo sistólico de la punta propagado a la axila. Scrplo diastólico en el II espacio irtexrstal izquierdo junto al esternón. Sigundo toro pulmonar acentuado. Abdomen: Higado en el teborde. Bazo se percute, no sz palpa. Sistema nervioso: Reficjas rotalianos conservados. exagatados ai jado derecho. Aquilianos consetvados. Babinsky disecho esbozado. Lligera desviakion de la boca hasia la iz. quierda. 
Evolución y tratamiento: Se hace hidroterapia y tónicos cardiovasculares. En la misma tarde del día de su ingriso, presenta bruscamente un ataque convolsivo. Empieza por contratciones titmicas del lado izquierdo de la cara, después se generalizan tomando todo el lado izquierdo epecialmenté el miembro inferior izquierdo. Las convalsiones daran alrededor de 3 horas. Termina el ataqaé con una rigidez espástica de todo écuerpo. Se queda en coma hasta el día siguiente en que fallece. Se hizo punción lumbar, cuỵo sxamen revela: aspecto turbia, albúmina 0,60 . pandy ++ , nonne zppel $t$, ros: jonas + . weichbradt + . cloruros $7.10 \times \mathrm{mil}$. leucocitos $2,880 \mathrm{x} \mathrm{mm} .3$. Las siembras fueron estériles desoués de varios días de observasión.

Autopsia: Protocolo N. 76. 1935. Endocarditis crónica fibrasa valunlar y cordal de la mitral $y$ endocanditis rexurrente vegetante discrata da la misma. Endocarditis fibrosa di-creta de los velos aorticos. Fcco de encefalitis purulezta hemorrágica del bemisferio izquierdo situado on la cápsula interna po: por fuera de la parte ancerior del tálamo óprico (enesfalitis embólica diseminada). Leptomeningitis parulenta diseminada. Hiperplasia de la pulpa as plénica. Bazo pesó $92 \mathrm{gts}$. (sepsis). Bronquitis purulenta y pequeños focos de bronconeumonia dizemitado; en el puimón dereho. Exśments bistológicos: Corte de válvula comprendiendo la pequeña masa vegetarta: el tejido valvalar aparem ce engrosado por fuerte desartollo def conjunte el cual en algunas zonaj (la cercana al depósito superficial) aparecs disgrzgado por un edera e infiltrado inflamatorio. Se encuertran a esti nivel abundantes vasitos. La superficie aparece recubierta por grusos depósitos de fibrina que en parte contraen fuertis adherencias con la váloula que comicnza a organizariz. En esta capa de fibrina eoptcialmente hacia la superficie. se encuentran abundants leucocitos. Corte de arteriola trombosada y cerebro: $S u$ iumen se encuentra totijenente ocupado por un trombo purutento que se adhiere a las paredes vasulares. En la adventicia existe una fuerte reacrión inflamatoria. Lon vasos vacinos intensamente hiperhemiados y cn relavión con fa sustancia carabral se ven numerosas hemorragias, algunas puntiformes, otras má; extendidas. También en el tejido cerebral cercano se observan. ademas, grandes infilteados leucoctarios (encefalitis purnlenta, hemortágica).

ICASO N: 4.-ZElba T.: 8 años. Bol. 20.290. Ingresa el 11-1-39.

Anteardentes: Padres Wass. (-). Han sido 12 hermanos, 8 muertos te trastornos nutritivos, escarlatina, bronconcumonía. 2 abortos espontáneos. Sarampión hace 4 años. El $5-X-38$ consulta en la Policlínica de enfermedades cardiacas y reumáticas por dolores en la articulacion tibiotarsiana derecha $Y$ disnea de effuerzo. Al examen se encuentra temperatura de $371 / 2 \%$, pulso de 108. presión (erkameter) $105 \times 615$. Cotazón: punta late en el V espacio por deatro de 1 línea mamilar. Soplo bolosistólico rudo de la punta que se irridia a la axila y rengión mesocardiata. Segundo tono pulmonar de la base tefo:zado, Abdomen normal. Caries de $4 .^{\circ}$ grado. Velocidad de sedimentación (Wrstergreen). $45 \mathrm{~mm}$. en 1 hora. Radioscopía del tórax: Hilios matcados. Sombra 
situada en la rogión del ángulo catdiodiafragmático que no permite distinguit con precisión el limite del corazón. Parece existir una aldherencia plearopericardiaca. Sombra cadiaca ligeramente aumentada. Telediagtarna: Diam. trans. 9,4 (?); diam. Jong. 9.7; diam. baial 8.7 im. Hemograma: bematíes, 3.700,000; leucocitos, 12,300: bas., 0,5: eos., 4: mie. 0 : juv., 0 ; bac., 1.5: seg., 671/?:? lin., 24/2: mon., 2. Se deja en reposo absoluto en cama y salicilato de sodio 4 grs. diarios. La carditis aguda pasa más a menos rápidamente 7 así, en su nueva consulta del 28-XI-38. persiste ta intuficiencia mitral, la velocidad ta sedimentatión, el hemogtama son normales.

Enfermedad acqual: Desde bace 15 dias presenta dolores cambiantes en las todillas. hueco popliteo, attioulaciones radiocatpianas: codos y tibiotarsianus. En su casa se le administró salicilato de sodio, sin experimentar mejoría.

Examen físico: Niña enflaquecịda, tamp. 38,4\%, resiraciones 30 . Cabeza: Bien conformada, conjuntivas limpras, pupilas reaccionan bien. Lengua saburral. Dentadura en mal estado. Faringe y amígdialas normales, Prlmones: nada de especial. Abdomeat Húgado y bazo normales. Sistema cardiovascular: taquicardia de 110. regulat. Presión $12 \frac{1}{2} \times 6$. Corazón: Punta late en el V espacio por dentro de la linea mamilar. Soplo holosiltólico de la punta irradiado a la axila. Segriodo tono pulmonar atentuadc.

Evolución y Tratamiento: Se trata con piramidón $1,50 \mathrm{gr}$. diarios. Ia temperatura cae al sigundo dia, para mantenerse normal por 9 dias, el puisose manciene alto $y$ aun tiende a subic basta 120. Velotidad de sedimentación: $47 \mathrm{~mm}$. en l hora. Examen orina: abbưmina, inditios; hematís, ило que otro: El 19-I-1939-sobreviene bruscamente un ataque convalsivo con pérdida del conocimiento. Al día siguiente el examen revela: Parálisis facial y de ambos miembros izquierdos. desviación de ambos globos oculares hacia la derecha. Reflejo comeal aboido a izquitirda. Papilas dilatidas más a izquierda, reaccionan flojamente a la laz. Reflejos abdominales y rotuliano abolidos a izquierdo. Babinsky positivo en ambas lados. Desriación de la lengua hacia la izquierda. Higado grande a 3 trives:s des reborde costal. Bazo grände, duro, se palpa a 3 traveses del reborde costal. El pulso desciende a 90. las respirationes allmentan a 40 y la temperatura comicnan a ascender. Examen orina (20-I-29): albúmina, indicios: glucosa. 3 gra. x $0 / 00$ : leucocitos, ++ : hematies, ++ . Hemograma (16-[-39): hematies, 3.400,000; leucocitos 16,000; bas., 0; cos., 0.5; mie., 0; juv., 5.5; balk.. 23: seg., 66; lin., 3; mon.. 2 .

La enferma continuó hasta su muerte, el día 27-I-39 en estado comatoso. Se bace punción lumbar al $80^{\circ}$ dia de sa temiplagia, uque da salida a $25 \mathrm{ec}$. de liquido xantoctómico. cuyo examis revela: abbrimina. $1 \mathrm{gr}, \mathrm{x}$ 0/00: Pandy +++ ; Noune +++ : Ross Jones ++ : Weichbrodt ++ ; cloturos, $6.8 \mathrm{grs} . \mathrm{x} 0$. Es retirada por la familia y no fué posible practicar la antopsia.

CA.SO N. 5.C. H. : 10 años. Bol. : 20,305.41/1916. Ingresa: 13-I-39. Antecedentes: Madre: Wass, negativo, sana. Padre abandonó el hogar. 3 hernanes sinos, 3 abortos. Nació en parto de término. Caqueluche a los 6 años. 
Sạtampión a los 8 años. En st itivizno de 1926, dolores musculares, En 1937 , dolores en ambas rodillas sin tumefacción. No guardó cama. Examinada en la Siction Cardiclogia del Departamento de Sauidad Eicoliat el 27-IX.37 se en:uentra en el corazón, an choque de la punta en el $V$ espatio por faera de la linea mamilar. Soplo bolosistólico rudo en ese sitio, irtádiado a la región axilar izquicrda. El tclediagrama demuestra un aumento mediano de las cavidades cardiacas: configuración gencral mitrálica. Se hace el diagnóstico de enfermedad reumática, insuficiencia mitral.

Enfermedad actual: Dos dias antes di su ingreso (11-I-39), en circunstancias que i.e innia en parfecto estado de salud, sirnte en forma mas o menos brusça adormecimicnto dal brazo y de la pierna derecha; desde esz momento no pudo andar, la palabra se hace dificulcosa. E1 12-1-39 aparecen vómitos. cefalas y Habre, por to que decide ingresar al thospital.

Examen fisico: Buen sstado nutnitivo, posición pasiva, sensorio despejado, tomperatura 371/2\%. Cabeza: ibien conformada. Ojos, nariz y oídos: nada de esFetial, Boca: Faringe roja, con secreción puruinta tetronacal. Dentidura in buen estado. Ganglios: microadenia cervical superior. Pulmones: nada de espiciâl, Corazón: [aquicardia de 100 . Presión (tonometer) $15 \frac{1}{2}$ x $8 \frac{1}{2}$. Punta late en el IV espacio a 1 c.m. por dentro de la línea mamilar. Soplo lwolosistólico de la pusta irradiajo a la axila y región mesocardiaca. Acentuación del II tono pulmonar en la base. Abdomen: Blando y depresible. Hígado a un través de dedo del reborde costal. Baza: grande, a dos traveses del reborde costal, bastante daro. Sistema nervioso: Parálisis de la extremidad superior derecha con abolición de los reflejos, excepto el olcoctaneano. Parálisis de la extremidad interior derecha con disminución del reflejo roruliano, exístencia del aquitiano. Reflejos rotuliano y aquiliano exaltados at lado izquierdo. Babinsky positivo en el lado deredbo, no hay clonus. Sensibilidad tácril térmica y profunda, normales. Extremidades: Choque rotuliano izquiendo. Dedos hipocráticos de II grado.

Evclución y tratamienta: Se trata con piramidón y una serie de 5 transtusiones de sangre. En el $30^{\circ}$ y $5 .^{\circ}$ dia de su hospitalización, prosentó dos ataques convulsivos localizados a la mirad derecha del onempo. Sedimentacion de los bematies, $43 \mathrm{~mm}$. Examen orina: albúmina, $0.20 \mathrm{gr} .0 / 00$; humatís, ++ . Fondo de ojo normal. Hemograma: bematies, 4.260,000; leucocitos, 6.300; bas..

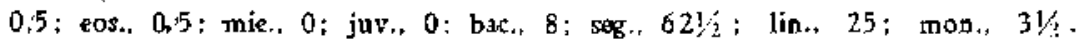

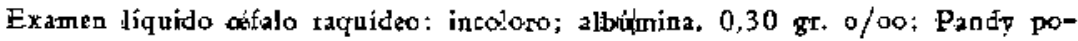
sitiva débili Nonne Appelt positiva débil; Ross Jones afgativa; cloratos, 7,4 grs. o/oo; nomo mastic, curva negativa; Wass. negativa: 0,1 ledcocito por mm.3; hematíes. 165 por $\mathrm{mm} .3$.

La patálisis va cediendo poco a poco. la niña puede caminar, pero lo hace en matoha bemiplégica, El bazo aumenta de tamaño thasta 3 traveses del reborde costai. La temperatara, periodos afebriles y periodos febriles, hasta $38^{\circ}$. EI pulso osciló entre 100 a 120 . La australtación cardiaca sin modíficación. Es retitada a $\operatorname{los} 42$ dias de brospitalización el 23-[T-39. 
En su control ambalatorio posterior, la nifía es mantenida en muy buenas condiciones, aparentemente sin accidentz embólico. El examen niurológico prarricado en VII-4.1 por et Dr. O. Olea, revela: En la lara sólo so aprecia un Chrostack positivo intenso bilataral. 'En las extromidades superiores las furrzas estan bien conservadas y sólo sa aprecia una ligeta diferencia de los teflejos tadial y tricipital, siendo más vivos a la detzcha. En las extremidades inferiores. 'As fuerzas se notan bien conservadas. sin embargo. en el lado izquierdo, tas masas mutculares están más desarrolladas yue a la derăha. E1 pie derécho está algo caido por contractura da los gemelos. Clonus del pie a dercha. Babinsky posirivo, Refiejo patelar derecho musho mayor que a la izquieada. Reftejo contr3lateral de los adductorts positivos en ambos jadios. LMaticha con nua elaudicausión semejante a la de los luxados de la cadera en el lado derraho. Al hacerla paratse en la extremidad infirior deretha: se baja un poco la pelvis (parälisis glútea). Enfrialmiento de la pierna derédha. IRefiejos abdominates normales. No hay trasiornos de la sinsibilitad. Conclasion: secueb matora de naa lesión central del lado izquierdo del cerebro por hemotragia o embolia. Examen orina (17-Vh-41): albúmina, indicios ligeros: leucocitos, mus escasos; hematíes, muy esiasos. Himogranu (2-VIII-41) : hemities, 5.030.000; hemoglobina, 16.3 gxr. c/r; plaquetas abundantas: leucocitos. 7.800 ; bss., 0; eos., 31\%:

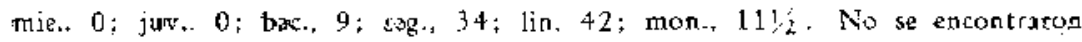
células sndoteliales en el frotis d: la oreja. Hemotultivo (16-VII-41): Hubo desarollo de estreptocoso no hemolítico. En su cyontrol del 29-VII-4l se encuct:tra, fuera de su espiencmegalia a 3 travese del xbordit dura petequias in la partie anterior y superior del. tórax. Numorosas petequias conglomeradas en el Faladar blando.

CASO N゙: 6.—E. M.: 9 años. Ból. 20.619. Ingresó a'j 1 l-II-39.

Antecedintes: Los pidres se iguoran. iLa niña es adoptada por la persena que la rraz al bospital. Sarna hate 3 meies. Dolores articulares desdi dos mesis

Enfecmedad actual: Consulta cn la Policlinica el 1.9-LI-39 por edema de las extremidades inferiors' ly de la cara, que habian inicrado desde hace 1 mes. Elemintos coino de uriticaria en las extremidades, desde thace 3 dias. El examen de arina revela: albúmina, 0.40 ; hematíes, ++ ; Eilindros gratrulosos.

Examen físicu: Enflaquecida en posición activa júcida, temperatura $38.6^{\circ}$. Cabeza: birn conformata, ojos normates. Bcea: dentadura in mal estado. Cuello: danza arterial. Palmones: Escasos estrrtores sibilantez diseminados en ambos campos pulmonares. Sistema cardiovascular: Taquicardia de 130. palso regular. celer. Presión 10\% x 5 (Tonometer). Corazón: Pusta se ve y se palpa en el V espacio a nivel di la finea mamilar. Sopto sistólico de la punta irridiado a la axila, soplo tfresistólico de la panta. Soplo diastólico a rivel del Il y III espacio jzquierdos junto al esterrón. Tendencia al desdoblamiento del segundo tono de la base. Reforzamiento del ségundo tono pulmonat. $\mathbf{A}$ domen: T'impanizado ton cierta defanga a la palpaxión. Hígado al través de dedo del reborde costal. Bazo se palpa en el reborde tostal. Extremidades: 
Ligero edema de las extrimidades inferiores. Dedos en papillo de rambor. Piel: Elementos urticariales del antebrazo derecho en su parte interna. Artículaciones: Dolor en el bombro derecho a la paibración; en las vértebtas cervicales, dolor a los movimientos.

Evolución y tratamiento: Piramidón, $1 \frac{1}{2}$ gr. diarios. Desaparzecen los do'ores articulares, Sedimintación, $76 \mathrm{~m} . \mathrm{m}$. Hemograma: hematies. 4.020.000; leucocitos, 8,900: bas., 0; eas., 0 : mie., 0; juv., 5; bz'c., 47: seg., 22; lin.. 20: mon., 6. Examen de orina: albúmina. 0. 20; gycosa, acetona, no hap: urobiina. indicics: cloruto-3, 8.5: nrea, 12.81: leucocitos, escasos; hematies. r.gular cartidad: cjlindros hialinos, eccasos. Desde el dia siguiente de su ingreso, la tamperatera se bace normal hasta el $18-\mathrm{ill}$, en que akanza a $39 \% \mathrm{~s}$. El bazo aument x poco a po:o de tamaño, a 2 traveses ei 16-IL y a 4 traveser i1 18-HI-39. E1 22-II-39 scbreviene brascamente an ataque, con pérdida del conocimiento, vómitos y contraccionej tónico-clónicas. después del cual se instala una parálisis faciall derectha y themiplizgia del mismo lado. El pulso se hace más linio, los soplos eardiacos más ásperos. Examan oriad: albúmina. 0.20 ; giusosa. indicios; urobilin', indscios; cloruros, 4,3; urea, 12.81: globulos de pus muy escasos: hamaties. regular cantidad: cilindros hialinos y granulssos, ascasos. Hemocultivo negativo después de 10 dias de incubación. Was. regativo. Hista re 28-I-?9. la hemiplegia persisté sia modificactón, aparece edema del lado paralizado: la temperatura oscila als:dedor de $38^{\circ}$. pulso de 80 . Un nuevo examen de orina revil ábúmina. I gr.; hematice, abundantes: cilindros hialinos y granulosos, escasos. En el corazór: a la sintomatología descrita. se agrega un piolemint de la punta. El

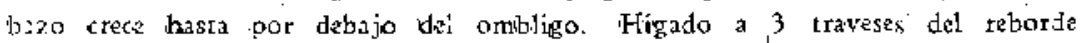
sosłal. Se bacz una punción lumbar a 1,-1.II-39, que da salida a liquito amariliento, con cierta prezión. cuyo examen dió: aspecto incoloro color xán1ricrómico; albúmitia. 0,40 : Dorne appelt $t$; rose jones $t ;$ cloraros. 7,4; g]u'cosa. 0.35: exiamen citológico: 88,4 hematís por $1 \mathrm{~mm} 3$; 12 leucocitos por mm.3.

Permanece en el servicio thasta of 17-III-39. Se mantient subfebril. hasta el 9-ILI. co que ramienza con un nuevo período febril de $38^{\circ}$ a $39^{\circ}$. Hemograma: hematies, 3.210.000: Teococitos, 10,000; bas.. 0; eos., 0 : mie., 0 : jov., 4!/2; bac., 61; sog. 231/1 : lin., 101/2; mon., 1/2. Aparecen deposiciones liquidas con abondante sangre, que cesan al cabo dz 3 dias. Es retitada por la familia.

CASO N.9 7,-I. IS.; 9 años. Bol, 40/2. Ingresó el 1.9-1-40.

Antecdientes: Padre alcohóliko, Madre sana. Ha tenido 7 hijos, 5 vivos. los hemanos son sarios. 2 muertos de trastornos nutritivos agudos 1 aborto espontáneo: Sin antecedentes de t.b.c., ni renmáticos familiares, Sarampión $y$ copueluche a las 4 años. En $L X-\$ 9$, cuadro poliarticalar agudo ftbril, con tumefarción dolorosa de ambas antieulaciones tibiotarsianas. Trata- 
do en su casa, la mo mestias cesaron al cabo de 15 dias. N'o sintió molestias hasta XIII-39, en que sobreviene un nucvo cuadro arícular, con fiebre. vómitos, dolotes abdominales e iotenso compromiso de las articulationes radiocarpianas, codos, hombros, rodillas y tibiotarsianas.

Enfermedad actual: En circunstarcias que el onadto articular había cidido, el 26-XII-39 instala en forma brusia una beniplegia izquierda con quálissis facial del mismo lado. Por esto se hospitaliza.

Examen físico: Enflaquecida, posición pasiva psiquis lúcido, temperatura 371/2\%, respiraciones 30. Pjel: Hiperestesia generalizada, Kbdomen: Tenso. doloroso. Bazo se palpa. Higado en el riborde costal. Pulmón: Nada patológico. Siscema cardiovascular: Taquicardia de 100, regular. Corazón: Punta se ve y se palpa en el V espacio a nivel de lì línea manilat, Prásión 11 x 5l/2. Frémito sistólico de la punta. Soplo sistólico intenso de la punta con propagación a la axila. Sistema nervioso: Hemiplegia cortical izquierda. Parálisis facial ierrtral izquierda. No bay signas meningeos. Hipertonia, reflejos exaltadios y cionus del lado izquierdo. Ojos natiz y oidos: Nada de eqpicial. Boca: Dentađusa en pésimo estado. Amígdalas nonmales.

Evolución y tratamiento: Se administra salicilato de sodio. 6 grs. diarios. por via bucal. En los primeros 10 dias, el cuadro no se modifica, tiende a agravare, la temperatura oscila entre $38 \frac{1}{2}^{\circ}$ y $391 / 2^{\circ}$, pulso 120 a 130 . El higado anmenta hasta 2 traveses del reborde costal. Bazo se palpa. La hemiplegia no cede. Hemocultivo negativo. Wass. y Kahn negativos. Orina: Albúmina, indicios; glacosa, acetona, áxido diacétíco, no hary; indican, eabundante; urobilina, indiciox clorufos, $3,2 \mathrm{grs} . x$ mil; urea, 10.24 grs. $x$ mil: thematies, escasos: broterios, abondantes, Harnograma: hematizs, 3.340.000: hemoglobina, $12 \frac{1}{2}$ grs. \%; plaquetas, mury disminuidas al frotis; leucocitos. 18.700: bas. 0 : cos., 0 ; mie., 0 ; juv., 9: bac.. 271/2: etg.. 42; lin., 151/2; mon., 6: anisocitosis, potiquilocitosis, politromasia. En la fórmuta leucoc:tatia del lóbulo de la oreja no encontracon células endoteliales.

A mediados de Enero, comienza a aparecer edema del miembro inferior iziquicndo, ligera ascitis, y en el corazón se ausculta un doble saplo de la panta. Sedimentatión de $44 \mathrm{~mm}$. Continúa la temperarura alta. La divresis tiende a dismirtuir. Se contirúa con satitilato de sodio $y$ se agrega digital $y$ teobromina. Pasa por periodos de mejoria, paral nuevamente agravarse. E! hígado sigue aumentando hasta 6 traveses. El bazo en el reborde costal. HRmocultivo negativo por segunda vez. Un tuevo hemograma revela: hematies, 2.010,000; hemoglobina, 7,3 grs. \%; leucocitos, 13,300: bas., 0; eos. I; mie., 0; jurv., 1/2: bak., 401/2; seg.. 47; lin., 8; mon.. 3; agtisocitasis, pciquilositocis, eritroblastos ortoctomaticos. $0.5 \%$. E1 $10-\mathrm{II}-40$ aparecen en las extromidades elementos pépulo-eritematosos paqueños con el centro blanquecinc, El 12-H es retirada por la familia. Nuestra información es que falleib al dia siguiente. 
CASO N.P 8.-C. G.: 7 añ'os. Bol. 40/2932. Irugresa el 14-XI-40.

Antecedentes: $1 .{ }^{7}$ hospitalización: Acude al hospital el $25-$ III-37, porque desde bacía 17 dia's estaba con un cuadro febril, disnea y tamefacción dolorosa de las articalaciones radiocappianas y codos. Se trata con salirilato de sodio $y$ piramidón en curas alterradas. Como enfetmedad intercurrente, tiene una pleuritis mediastino diafragmát kea derecha. Se da de alta el 21-VilI-37 ('a los 117 dias de hospitalización) con el diagnóstico de Poliartritis reumática aguda y enfermedad mitral. 2-a hospitalizución: E1 $21-\mathrm{LX}-37$ ingrela por disnea de esfuerzo $y$ de decúbito. Se trata con piramidón $y$ digitalina. Aita a los 67 dias, el 26-XI-37, ccn el diagnóstico de enfermedad mitral. Hiposistolia inflamatoria (mictard.). Sigue su control an la Policlinica de enfermedades cardiacas y reumáticas, en conde en Enero de 1940 se comptueba una enfermedad mitral y una insaficiencia aórtica. La familia se va fnera de Santiago. No hay disnea d: esfuerzo. 3." hospitalización: Dos dias antes de su ingreso (12-XT-40) are bruscamente con vóraitos, cefaleas, intensa adinamia y fieb:e.

Examen fisico: Niño en pośción atetiva, pálido, temperatura $381 / 22^{\circ}$, estado tífico. Respiración 30. Piel': Nameroses petequias diseminadas, especialmente cn 1 a parte suparior del tórax. algusas en el cuello cuero cabelludo. Algunas cicatrices de impétigo. Ganglios: Mikroadenia inguinal, axilar y cervical. Abdomen: Ligeramente deprimido. Hígado a 3 traveses del raborde costal, ahgo doloroso. Bazo se pencute, no se palpa. Pulmones: Nada de especial. Sistema cardiovascular: Taquitardia de 140, pulso regalar, blando. Presión (tonometer) Il x $41 / 2$ H. D. Rampel-Leedf ++ . Cotazón: Ligero abombamicnto del themitórax izquierdo en la togión precondid. Punta late en cúpula a nivel dal VI sopacio intercostal a $1 \mathrm{~cm}$. por fuera de la Jínea mamilar. Soplo hoiosistólico intenso de la punta irradiado a la axila, al bipocondrio izquierdo y al dorso. Soplo diatólico a nivel del II y III espacio intersostal izquiendo. junto al esternón. Sistema nervioso: Roflejos tendinosos disminuítos. No se Encuentran sigaos meningeos. Ojos: Pupilas reaccionan bien, desartollo mareado de rasos en la conjuntiva. Boca: Dentadara en mal estado. Lengua saburrat. Faringe roja con sécreción purulenta retronasal.

Evolución y cratamiento: Se trata con piramidón 1,20 diarios. Sedimentación, $27 \mathrm{~mm}$; R. Widal, paratifus y Weil-Félix, negativas. La temperatura cat a la normal al día siguiente. El estado general se va agravando pantatinamente, instalándose obnubilación zensorial. El bazo comienza a palparse en e) reborde costal. El palso se hace túa a dia más rápido, a pesar de la digital que thutbo de ạ̛ministrarse. Examen orina (18-XI-40): albúmina, 1 ge; hematies +++ : Kahn, negativo. Hemograma: hematíes, 4.100,000; hemoglobina, 13.1 gr. \%: plaquetas, abundantes; leucocitos, 40.000 ; bas., 0 ; eos.

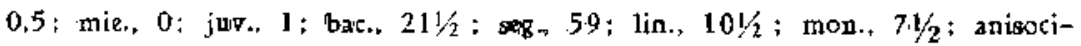
tosis y alteración degenerativa de los neutrófilos. Radiografia torácica: campos putmonares, sombea cardiata aumentada, en espacial el ventrículo izquier- 
do. Hemocultivo: infectión secundaria. El 20 y $21-X_{1} I-40$ presenta nuevamente fiebre hasta $381 / 2{ }^{\circ}$. taquicardia de 345 , la disnza aumenta a 45 , vómitos frecuentes. Corazón: ondulación de la región precordial; punta late en el VI espacio a dos travases de dedo por fuera de la línea mantitar, ruido de gaIope; frotes pericardíacos localizados en la punta. Boca: Punteado petequial en el yelo del paladar. Bazo se palpa. Se encuentra ligera rigidez de nuca, por lo que se practixa unal puritión lumbar, que da salida a líquido claro con albúmina, 0.20 gr. o/00; giobalinas, negativas; cloruto:, 7 grs. $0 / 00$; ex. citológico: 58 leucacitos por $\mathrm{mm} .3$; monocitos, $0 \%$ : linfocitos. $75 \%$; polinucieaxes, $215 \%$. Examen orina: albúmina, indicios; gluxosa, acetona, no hay: thematies +++ : bacterio; + ; cilindros bialinos. uno que otro. Fallece it 22-XII-40

Antopsia: Protocolo N.? 195, 1940. Abierto el pericardio, sus hojas se encuentran ligetamente engrosadas batia la parte anterior del corazón, cerca de la punta', ee encuentran atherentiàs firmes del perikandio que no es posible desprender (sinfisis pericardiaca lacal). Haciendo ol corti habicuai de la punta del corazón. se encuentra éste en ejtado diastólićo, la pared del ventriculo izquierdo in el corte de la punts miłe $6 \mathrm{~mm}$.: ventriculo derecho $1 \mathrm{~mm}$. Abierta la válvala initral, aparece recubierta de masas frizibles amari'tentas como coliflores, estas misas avanzar haxia el endocardioparietai auricular, ésti en parte ptetenta pequeña úlcera de color amarillento turbio y bordes rojizos. se notan también los mismos dipó:itos blandos amarillentos a nivel de los velos aórticos, los que están engrosados y como carcomidos. lo mismo el resto de ly válvula mitrai engrosada (endocarditis crórica fiblrosa mitromártica y endocarditis recurtente maligna). Mickardio se presinta turbio a Ins cortes. Pulmones: Libres de ajherencias, se presentan de color rojo obscuro y hasta con pequ: más densas y de coloración roja más obscura, estas zonas ocupan gran parte de! lóbulo inferior derecho y región dorsal del lábulo saperior de este lado. Cavidad abdominal: ISe concentra un gran bazo, de consistencia blanda, que pesa $200 \mathrm{grs}$ (sepris). Higado grande hiperhemito, turbio. 'pesa 1.017 grs.. no bay cianosir. Vias biliares permeables. Riñones: Se encuentran en ello piequeños infartos corticales recientes. Están tumefactos y muy tubios. Ganglios mesentéricos hiperplasiados y de colorasión grisácea pálída. Mưcosa intestinal bien conservada: p.aca'; de Payer bien marcadas. Cerforo: Fuerie hiperhemis de 13 píamadre que en algunos puntas presenta zonas más rojizas $y$ turbias a los cortés presenta consistercia firme $y$ edema.

Examen microscópico: Corazón: Se encuentran engrosamientos del tejido conjuntivo perivascular y focos reciences de miocarditis intersticial embólica. Riñón: Infarto que necrosa una cứì de la cortical. alsedddor de él y en alganos puntos de su parte centrai. fort: infiltración leucozitaria. Intensa tumefación turbia de los tubulits tenales, Los glomérulos presentan aspecto normal en el resto del rírón. Algnnos en vias ide atrofia. Merlinges: Los vasos están hiperibemiados y repletos de leucociros polinucleares. Se hallan infiltrados in. 
flamatorios distretos de la piamadre (leptomeningitis). Pulmón: En los focos densos domina el edema, hemorragia en el interior de los alvéolos. también gtandes células calartales con pigmentos. En algunos alvéolos leucocitos y células redondas: piqueñas y picasas.

Ciagnóstico histopatológico: Endocarditis crónica fíbtosa mitro-zórtica y endorarditis recurente maligna (úlcero-vegetante). ISínfisis pericarchíaca localizada. Infarto rinal. Leptomeningitis.

Dr. Alberto Guzmán.

CASO N.P 9.-M. A.: 12 año:. Bol. 40/3226. Ingresa el $11-X I I-40$.

Antecedentes: Padre sano. Wass. (-) en 1928. Madre sana. Siete embarazos, todos de término, escán tcdos vivos y son saras. No acusa antecedentes morbosos anteriotes. El 5-IV-36 ingresa al Hospital Barros Luco, porque el dia anterior ciz bruscamente en inconsciencia. rigidez dz la nuca y exantema y tempetatura alta. Se sospecha en un tifus exancemático y se intema. Permaлec: alli hasta of 29-IV-36. la temperatura si, mantiene ortilando entre. 37\% $y$ $38^{\circ}$ ó $40^{\circ}$ : R. de Widal. paratifus y Weil-Félix negativas, Radioacopía pulnomar, negativa, Es trasladado al Hospiral M, Arriatán el 29-IV-36, en donde se comprutaba un niño erfiaquzcido ligeramente disnsico, labios y mejillas algo cianótico: dentadura en mal estado. Soplo sistólico intenso de la punta que se fropanga bacia la axila. Higado a $1 \mathrm{~cm}$. dal bork costal. Sin edemas. Pareze haber dolor a los movimientos articulare;. Se irata con salicilato de codio. Wass. (-). Homograma: hernaties, 3.760.000: leucocitos., 9,700: bas, 0: eos., 8; juv. 2; bac.. 12; azg., 52: lin., 24; mon.. 2. Examen ợina: albúmina, no ihay; glábulos blancos y kélulas epiteliates, escasos. R. Widal. paratifus y Weil-Félix, degativas. El electrocardiograma demuestra un bloqueo aurículo ventricalax parcial. Se da dic alta el 16-VII-36 con el diagnóstico de intuficiencia mitral teumática. Reingresa al mismo thospital it 27-X-36. Desde su salida ha continuado con vértigos, cefaleas intensas y segúr la madrs. a veces, imposibilidad para bablar. Durante la evolución de. la enfrimedad, no presentó fiebre. Examen orina (-). Durante su evoluzión bubo un brote remmático que se trató con salikitato de sodio. En in corazón insuficiencia mitcal, cor ligera hipertrofia cardiza. Se dió de a'ta el 3-II-37.

Enfermedad actual: Deslde hács 15 dias presenta edema de la cara $y$ mimbro; inferiores, edema que ha ido progrejando hasta generalizarse. Al mismo tiempo, la orina si hace obscura. Se cansa al menor ejercicio.

Examen físico: Niñio subfẹbrit. en posición activa. Piel: Anasarca. Petequias diseminadas. Abdomen: Hígado en el reborde costal. Bazo, no se pai$\mathrm{P}^{\mathrm{a}}$. Sistema cardioyasqular: Pulso traso, regular 90. Presión (tonometer) 15 $x$ 10. Abombaniento de la región précondia!. Se ren latías impnlsivos de ta punta. Latidos supraesternalés. Area de macidez cardíaca. Pụnta late fn el V espacio a nivel de la linea mamilar. Soplo tholosistólico de ta punta itradiado a la axila y a la base. Reforzamiento d:1 II tono pulmonar. Sistema nervio- 
so: Reficjos rotulianos muy vivos. Paresia facial dereoha. Ojos: estravismo divergente $O$. D. Reflejosc pupilares normalcs. Baca: caries drzbasias. Amigdalas poqueñas. Dedos bipoxtéticos de 1 ,er grado.

Evolución y tratamiento: Se trata con solución saturada de sulfato de mangnasia y régimen. Las orinas son francamente hematúricas. Examen orina: altúmlina. 10 grs. $\% / 00$ : bematies $t+++$ : cilindros granulosos y epiteliales ++ : hialinos + : urocultivo $(\rightarrow)$ : Wass. (-): uremia, 1,34 gr. $\%$ oo. Permanice en el servicio thasta el 17-X.II-40. Durante estos dixs, la temperatura permanece notmal, al igual que el pulso, pirsigte ta hipertensión y la hematuria. E1 I6-XII cae en un embotamiento sinsotial iy por periodos movimientos clónicos d: la mitad deticha del cuepo. El 17 amanece en coma profando. hemorragia por la boca. contractura del brazo dencobo. Se hace panción lumbar que da salida a liquido trangparente: albúnina, 0.70 gr. $o / 00$; Pandy $t+$; Nonne Appelt t: Ross Jones t: Weichbrodt + : elorures. 9,05 grs. o/oo. Examen citológico: 2 leucocitos por mm.3; hematies, 414 por mm.3. Fallece e! $18-X 11-40$.

Autopsia: Protocolo N. 226. 40. Abierta la cavidad abdominal se encuentra un gran bazo que pesa $185 \mathrm{grs,} \mathrm{de} \mathrm{consistencia} \mathrm{firme.} \mathrm{presenta} \mathrm{en} \mathrm{algu-}$ noj puntos de la superficie depresiones grisacess correspondisntes a infartos embólicos antiguos. Riñones presentan más bies aspecto ieregular. pesaron 70 grs. en derecho y 75 grs. el izquierdo: la captula está en parte adherida a la. superficie del riñon, al retirarla se fuede ver que esta pretental más fuertis adierencias a nivel de deptesiones superficiales grisáceas (infartos antignos). La sustancia cortical se encuentra atrofiada. Rińones al corte hiperbémicos. El limite de lia tustancia cortical y medular es borrosa, expicialmente en la supe:ficic se pueden vet numerosos puntitos rojizos, como picadas de pulgas. Hígado aumeñado de tamaño pesó $925 \mathrm{grs}$., suprefticie dz corte cusbia borros., no hay cianojis." Vias bjliares permeables, vesicula ligeramente hidrópica. Suprarranzle: en bueg istado de conservación. IPáncreas bien formado, de aspecto pálido a) corte, pesó 55 grs. En el mesentetio, los ganglios aparecen hiperhémiccs, aunque no muy aumentados de tamañio. Abirto el intrstino. la maciosa aparice intacta, sólo the aspecto edematoso.

En los pulmones se encuentran ajberencias es la rigión axilar del pulmón izquierdo a la pared costal, la cisura de este lado también adberida. Se enenentran focos rojizos derros d: bronconeumonia es la región dorsal del lóbulo inferior derecho. Ganglios peribronquilales están tumefattos e bipertzémicos. a] examen microscópico no se encontró taberzulosis. EI resto de los pulmones enfisematosos y con ligera antracosis, Corazón: Contraido. miocardio muy turbio al corte la pated del ventriculo izquierdo al corte de la pusta mide 6 a $7 \mathrm{~mm}$. La válvula mitral fstá en gran parte engrosada te aspecto blanquecino, presentando también en algunos puntos pequeñas verrococidades. que hacia la parte intorna de la valyula anterior avanzar hacia el endocardio parietal 
(endokarditis crónica fibrosa $y$ endorditis varrucosa recutrente). Los velos aórticos están eicaiamente engrosados, con un indicio de vascularización. Cerebro: Piamadre en gran parte hiperhémios turbiz, en algunoj puntos con prequeños puntos themorrágicos (leptomeningitis). En el lóbulo oxcipital-izquierdo hacia unos 5 cms, del polo posterior dat hamisferio aparece la corteza cerebral Inundida, como si tuviera una cavidad por debajo de alla. Haciendo un corte transvisal a este nivel se puede vet efectivamente una cavidad de paredes thuy limitadas, situadas por fuera de ta profongación occipital del ventriculo latetal, entre ésta y la corteza benebral. La superficie interna de ha cavidad es lisa y de color café. El pentrículo Jateral ate este lado dilatado, debido a la cavidad antes descrita. En algutos purfos la sustancia blanca se observa con punteado hemorrágico. Interpretamos esta cavidad como stcuela de ina embolia antigna.

\section{Dr. Alberto Guzmán.}

CASO N. ${ }^{\circ} 10 .-$ S. M.: 8 años. Bol. 41/130j. Ingresó el 13-V-1941.

Antecedentes: Padres, Wass. (-), sanos. Han muerto 5 hermanos nacidos en parto de término, de éstos, 3 muertos de "fiflbte"; el hicmano vivo es sano. No ba habidó aborto: Abuelita materna falleció hace 3 meses de probable t.b.c. palmonar. No bay antecidentas reumáticos familiare: Viatice'a hace 7 reses. Enfermedad infelcciosa exantemática hace 2 meses (descarlatina?). Hace 4 mzses poliartritis teumátła aguda, por lo que debió guardar cama darante 15 diagr tirmpo durante el cual la madre lo trata con fricciones. Posteriormente se sintió bien. molestindole sólo la disnea de esfuerzo que le quedara como secuela.

Enfermedad actual: Comienza hace mái o monos 1 mes. con fiebre. tumefacción do!orosa de la articalación tibiotarsiana izquierda, adinamia, disnea y tos. Guaríó cama agursos dias. Como en la ocasión anteriot se trata cor baños y fricciones, pero como el kuadro no pasara y lejos de esto, el niño st agrava deciden traerlo at hospital.

Examen físico: Niño enflaquexido, temperatura 37,89, respitaciones 28 . Piel: 3 piquzñias equimois indoloras localizadas en la cara interna de la pierna izquienda. Ganglios: Microadenia inguinal, del triángulo de Scanpa bilateral, axilar y cervical. Pequeños ganglios submaxilares y del ángulo especía:mente al lado izquierdo. Ricord bilateral. Esqueleto y extremidades: Dedos hipoxráticos de Il grado. Tumefacción dolorosa de la artikulación tibiotarsina izquicta, sin calor local ni cambio de colorzción de la piel; impotencia funcional con intenso dolor a los movimientos pasivoi. Tumefacción más discrata de la articulación tibiorarsiana derzha, con escaso dolor provocado. La movilización de la articulación coxolemoral izquierda es dolorosa. Abdanen: Paredes flácidas. Higado a l través del reborde costal, indoloto, borde sugom rior en el V eapacio. Bazo se palfa dificilmente endurecido. Siscema cardiovascalar: Taquicardia de 120, celer. Pre:ión (tonometer): $9 \times 4$ H. D., $9 \times 3$ 
H. I. Corazón: Area de maçecez cardiaca aumentada. Oridulación de la parci peecordial. Frémico sistólico y diastólico de la punta y región mzsocardiacz. Punta se palpa en el $V$ espacio intereostal izquierdo a nivel de a linea mamilat. Scplo holosistólico intenso y diastólico corto de la punta propagados a la axila. A nivel del. II ly III espacio izquicrdo junto al esternón, se ausculta un doble soplo intenso. E1 soplo diastólico de timbte aórtico, el sistólics tiene sa foco de maxima intensidad a nivel del II espario intercostal derecho junto al esternón $y$ se propaga bacia la clavicula $y$ mamelór del mismo lado, con menor intensidad hacia la clavícula izquierda $y$ al dorso, especialmente a dicscha. Palmones: Nada de expecial. Sisterna nervioso: Reflejos tendinosos vivos. No hay signos meningeos. Ojos. nariz y oidos: Nada patológico. Boca: Let:gua saburral, alitosis. Dentadnra en buen estado.

Evclación y tratamiento: Se somete a una cara salicilada con 5 grs. diarios por vía bucal, ILa evolutión do la enfermedad se haizo en bucnas condicionis: afebrit, priso 100 a 120, bruena diuresis; pasó el dolor articular, persistiendo la tumefacción. Lôs sintomas cardiacos sin variación. Examen orina: albúmina, indicios; benatirs, escasos; cilindros, epiteliales y granulosos. étasos. Kahn negativa. Sedimentación de los hamatirs. $100 \mathrm{~mm}$.' El teiediagrama nos demuestra sombra cardiaca aumentada, en especial el ventriculo izquiédo. Sombra aórtica alta $\gamma$ ensanihada con pulsacionts muy visibles. Hemagrima: thematies. 4.020.000: hemoglobina, 10.4 grs, \%/, leucocitos, 10,100: bas., 0 ; eos. 0 ; mie., 0 ; juv.. 0 ; bac.. 15\% ; seg.. 49: lin., $31 \frac{1}{2}$; mon., 3. anisoxitosis. Hemocultivo negativo desplés de 11 dias de incubación.

La teacción del niño al tratamiento hacia suponer una evolución más prolongada. E] $18-\mathrm{V}-41$ a fos 5 dias de hospitalizatción. en circunscancias que durante el día se había sentido bien, después de conversar animadamente con sus compañeros dê sala, tiene bruscamente una angustia intåna, sobreviene una marcada palidez, se intzlina bacia adelante $\mathrm{\gamma}$ fallece en esa posición.

Autopsia: Protocolo 85. 1941, Corazón: El área pericandiaca se encuentra aumentada, al tocarla hace la impresión de encontrarsi un liquido a tensión en su interior. A) abrir all pericardio, sale aburdante sangre líquida $y$, adcmass, grandes coágulos sanguíneos. El corazón está contraído. La pared da! ventrículo izquierdo en el corte de la punta mide $7 \mathrm{~mm}$. (hippertrofia disceta). La válvula mitrál presenta macrooxópicamenté aspictó y consistencia normal, presenta "sólo ligeras verrucósidades implantadas en el borde valuulax $y$. adomás, en el endoxandio parietal hácia la curicula (endocarditis recienté). Abizro el orificio aórtico y la aorta, se encuentran las siguientes alteraciones: llaman descle Juego la aterkión grindes masas verrucosas de coloración grís ama-

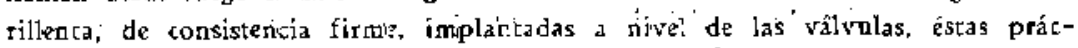
tramerte no' reconocen, éstán 'casi totalmente destruidas, quedando restos de elías que se toca may engrosados (secuela de una endidarditis crópica fibrosa antiguà): En el nacímiento de la aorta. en la región supra-valvular, se encuentra una gran destrucción olcerosa a ese nivel, que tiene hasta el tamaño de una moneda dé I0 centavos. Una delgada tela adventicial, formando 
ana membtan-a transparente, constituye el fordo de la destrocción de la pared aórtica. Una roptura manifiesta comunica el lumen de la dorta con ell pericardio, se pede observar nitidamente por transparenxia; una sonda acanalada corriente pasa fácilmente por la peforoción. Pulmones: Sólo se encuentra. adkerercias de la región dorsil del lóbalo inferior deredho. Los palmones están intensamente hiperhémicos y más bien enfisematosos sin focos densos. Abdomer: Se encuentra un bazo aumentado de tamaño, que peś́ 186 grs.; pulpa disminuida de consístencia. fólículos linfáticos están bien a la vista. Al corre. a nivel del folo superior ptesenta un infïrto antigno coneiforme, retraido en la superficie, y otros infartos rojizas más recientes vecinos a él. Abierto el estónago, se encuentra abundante contenido alimenticio. La mucosa intesti. tal está más birn pálida, en el intestino dìlgado se encuentra una pareja de cascaris. EI higado está hiperhémico turbio al corte y no presenta cianosis, pesó $850 \mathrm{grs}$. Los riñone; se presentan también tumefactos. biperbémicos turbios y también con infartos umbólizos antiguos cortinales, ligeräbnente retraídos. E1 riälón izquierdo es más grande que el derecho. pesó $70 \mathrm{grs.}$ y presenta dobie pelvis; el darecho, $57 \mathrm{grs}$. Cerebro: Prisenta consistencia regular y edema a los cortes. Autopsia de oído: negativa. Amígdalas, laringe, trácuea, nadal de especial.

Exámenes histológicos: Si pratica un corte que en parte comprende válvulas aónticas con las masas vegetantes $y$ la pared de la aorta hasta la ferforación. Las váloulas en gran parte se encuentran fibrosadas $y$ con pequeños va[oj de ncoformación, con zonas de necrosis superficial $y$ en inflamatión más recience, con abundantes leucocitos polinucleares. Además. exudado superficial fibrino-leucocitario abundante.

A nivel del nacimiento mismo de la aorta se encuentra un pequeño vasso trombosado y el corte príticado a lo largo de la aorta hasta la perforación demuestra signos evidentes de "necrobiosis difusa". Se trata, paes, de una altesación nectobiótica de la pared aórtica por embolia vecina que hlegó hasta la perforación diel valio (ver microfotografias).

\section{MIOCARDITIS EMBOLICA'}

En los cortis de corazón se enconteaton focos múltiple; de miocarditis embólica recientes $y$ más antiguos.

Dizgnóstico anatómico: Endocarditis xrónka fítrosa de los velos átticos y endocarditis úlcero-vegetantc returrente. Ruptura de la dorta. Hemo-pericardio. Endorardilis verrucosa reciente de la mitral. Infartos embólicos antiguos y recientes dal baxo, riñón ig mioxardiọ.

Dr. Rlberto Gozmán. 


\section{Bibliografía.}

E. BOUOHUT: Clinique de 1'Hopital des enfants malades, J. B. Bailliere et fils, París, 1884 .

E. PRADO TAGUE: Arth, de ta Clin. Midica, 1925.

ROST W. L, and FISCHER A. E.: Am. J. Dis, Child, 36:1144, 1928.

J. DAINERI: Rev. Chilena de Pediatria, N.: 5. 1930.

A. GARRIETICN SLLVA: Rev, Méd. y Alimentación, No 5, 1934.

R. INFALNTIE YAVAR: Arth. Hosp. de Niños "Roberto del Río", N.93. 1935.

M. ACUNA $y$ A. FUCilliSI: Atith. Atgent. Ped. Nios 9 y $10,1936$.

GROSSMAN A. and LIIEBERSON: A.: Am, Heart J., Nor. de 1937.

DUMAS A. DIDIER. LAUURENT et BERTHALL: Lyon Méd. N. ${ }^{\circ} 31,1937$.

LIAN C. MOULANGUUET P. T BROCARD H.: Press, Med. N:9 97, 1937.

CORINIL L. at JOUVEE A. X.: Press. Med., 30-X-37.

GROSS L. and FRED B. M.: Am. J. of P:lth 12:769. 1937.

A. SEEGERIS. J. L. MONSEIRRIATT hy ottos: Atith. Attgent. Ped., N. 2. 1939. HORLAER: Lancet. Julio de 1936.

HODES H. L, and GIMBEL .H. S.: J. A. M. A., 28-X-1939.

FRIEDMAINN M. HAMBURGUER W. W. and KATZ L. N.: J. A. M. A.. 4-XI-1939.

KELSON S. and W.HITE P. D.: J. A. M. A.. 4-XII-1939.

MAJiOR R. H.: Ain. J. M. Sc., Junio de 1940.

KEEFFER Ch. S.: Am. Heart J., 19:3.52, 1940.

ORAVEN E. B., POSTON M, IA. and ORGAIN E. S.: Am. Heart J., 19:434. 1940.

WRIGHT J. and AEIEK P. M.: Am. Heart J., 19:587, 1940.

LICIHTIMAN S. S. and BIEIRIMAN W.: J. A. M. A, 116:286, 1941.

BIERMAN W. And BAJEHIR G.: J. A. M. $\AA ., 116: 292,1941$.

CHRISTIAN H. A.: J. A. M. A., 116:1048. 1941. 